\title{
Impact of sub-mesoscale physics on production and subduction of phytoplankton in an oligotrophic regime
}

\author{
by Marina Lévy ${ }^{1}$, Patrice Klein ${ }^{2}$ and Anne-Marie Treguier ${ }^{2}$
}

\begin{abstract}
Using a protocol of numerical experiments where horizontal resolution is progressively increased, we show that small-scale (or sub-mesoscale) physics has a strong impact on both mesoscale physics and phytoplankton production/subduction.

Mesoscale and sub-mesoscale physics result from the nonlinear equilibration of an unstable baroclinic jet. The biogeochemicalcontext is oligotrophy. The explicitly resolved sub-mesoscales, at least smaller than one fifth of the internal Rossby radius of deformation, reinforce the mesoscale eddy field and contribute to double the primary production and phytoplankton subduction budgets. This enhancement is due to the reinforced mesoscale physics and is also achieved by the small-scale frontal dynamics. This sub-mesoscale physics is associated with density and vorticity gradients around and between the eddies. It triggers a significant small-scale nutrient injection in the surface layers, leading to a phytoplanktonfield mostly dominated by fine spatial structures. It is believed that, depending on wind forcings, this scenario should work alternately with that of Abraham (1998) which invokes horizontal stirring of nutrient injected at large scales. Results also reveal a strong relationship between new production and negative vorticity, in the absence of wind forcing and during the period of formation of the eddies.
\end{abstract}

\section{Introduction}

The earliest satellite color images (Gower et al., 1980) revealed spatial variability in the surface chlorophyll distribution at scales close to the first internal Rossby radius of deformation $\left(R_{d}\right)$, which is the characteristic scale of the mesoscale eddies (this length scale, $\sim 20-50 \mathrm{~km}$ in the mid-latitudes, is hereafter referred to as mesoscale). They also revealed a spatial variability at smaller scales $(\sim 5-20 \mathrm{~km}$, hereafter referred to as sub-mesoscale). Spectrum analysis performed on these sea surface chlorophyll images (Gower et al., 1980) showed $\mathrm{k}^{-3}$ slopes between the mesoscale and the sub-mesoscale, suggesting that sub-mesoscale features are much less energetic. However, more recent satellite images with a higher spatial resolution have revealed much more energetic sub-mesoscale features, with a $\mathrm{k}^{-2}$ spectral slope (Denman and Abbott, 1994) or $\mathrm{k}^{-1}$ slope (Vigan, pers. comm.), which leads to questions about their contribution to the new

1. Laboratoire d'Océanographie Dynamique et de Climatologie (LODYC), Université Pierre et Marie Curie, BC 100, 4 Place Jussieu, 75252 Paris Cedex 05, France.email: marina.levy@lodyc.jussieu.fr

2. Laboratoire de Physique des Océans (LPO), IFREMER, Centre de Brest, B.P. 70, 29280 Plouzane, France. 
production budget. More precisely, since this budget mostly results from the nutrient injection into the euphotic zone, the question is: do the sub-mesoscale features in the phytoplankton field come from the deformation and horizontal stirring by the eddies of nutrients injected at large-scale or mesoscale as suggested by Abraham (1998) or do they result from the impact of small-scale physics on nutrient injection in specific regions of the mesoscale eddy field? In the latter case small-scale physics should affect the global new production budget.

This question about the impact of small-scale physics also stems from recent numerical results. Indeed numerical studies of the past few years (Flierl and Davies, 1993; Yoshimori and Kishi, 1994; McGillicuddy et al., 1995, 1998; Smith et al., 1996; Dadou et al., 1996; Oschlies and Garçon, 1998; Lee and Williams, 2000; Lévy et al., 2000; Mahadevan and Archer, 2000; Anderson and Robinson, 2001) have clearly identified the role of the mesoscale eddies in the mesoscale injection of nutrients within the euphotic layer. The magnitude of the resulting effect was found to increase the preceding numerical estimates of primary production at large scale by up to $30 \%$ and thus to produce figures closer to the observations. Some of these studies have also highlighted the role of mesoscale physics in increasing the subduction of phytoplankton. Indeed, as for the injection of nutrients within the euphotic layer by upward transport, downward transport exports phytoplankton from the euphotic layer. However, all of these studies have made use of a numerical resolution (not smaller than $R_{d} / 4$ ) which represents the mesoscale well but poorly resolves the sub-mesoscale. Some of them (Lévy et al., 2000; Mahadevan and Archer, 2000), however, suggest that sub-mesoscale physics could have an impact on the production budget. Thus, Mahadevan and Archer (2000) found a systematic increase of production with the model resolution and concluded that vertical transport of nutrient-rich waters in regions near Bermuda and Hawaii takes place mainly at mesoscales and possibly even at frontal sub-mesoscales. But their resolution was not small enough to quantify the role of the sub-mesoscale. The recent study of Spall and Richards (2000) is the only one that explicitly resolves the sub-mesoscale by using a resolution of $\approx R_{d} / 9$. Their interesting and detailed results clearly reveal the production of small-scale features in the phytoplankton field. Nevertheless, it is still difficult to figure out, from their study, the explicit impact of small-scale physics on phytoplankton production and subduction.

A last motivation to question the impact of small-scale physics comes from some results in ocean physics. Halliwell and Cornillon (1989) and Pollard and Regier (1992) observed sub-mesoscale temperature features, as multiple time dependent frontal bands of $O(10) \mathrm{km}$ width, along the perimeter of mesoscale eddies. Their results suggest that the deformation field provided by the eddies is in part responsible for the existence of strong small-scale temperature gradients. Wang (1993) and Spall $(1995 ; 1997)$ have extensively investigated the time evolution of these sub-mesoscale features and characterized their associated strong vertical ageostrophic circulation (since their relative vorticity can be of the order of the planetary vorticity). It is, therefore, expected that the ageostrophic circulation associ- 
ated with these small-scale dynamical features can affect new production and phytoplankton subduction.

Consequently, the present study is a process study that explicitly focuses on the role of sub-mesoscale physics on phytoplankton production and subduction. For that purpose the dynamical context considered concerns a field of oceanic eddies that strongly interact since it is well known that such sub-mesoscale physics results from the nonlinear interactions between mesoscale eddies. This field is classically generated as the outcome of the nonlinear equilibration of an unstable baroclinic jet. The experimental protocol, chosen to selectively assess the impact of the sub-mesoscale structures, consists of progressively increasing the horizontal resolution. We examine the impact of numerical resolution produced by a coupled physical-biological model with a resolution varying from $R_{d} / 3$ up to $R_{d} / 20$, with $R_{d}$ the Rossby radius of deformation equal to $30 \mathrm{~km}$. This allows us to characterize the respective effects of mesoscale and sub-mesoscale dynamical features on the ecosystem. This chosen dynamical context does not pertain to a specific oceanic region. It pertains to regions where the dynamics is dominated by mesoscale eddies that strongly interact. Such regions involve not only the Gulf Stream, the Azores Front, the Antarctic Circumpolar Current, but also other regions as those revealed by recent satellite data (Stammer, 1997; Wunsch, 1997). The biogeochemical context is oligotrophy, which is characteristic of mid-latitude sub-tropical gyres and of summer situations in northern latitudes.

The simulations have revealed that an intermediate resolution $(6 \mathrm{~km})$ is sufficient to simulate the characteristic mesoscale structures. However, a much higher resolution $(2 \mathrm{~km})$ leads to a significant increase of new production and subduction, which enlightens the important impact of sub-mesoscale physics. The simulations are described in the next section. Then, the dynamical regimes are analyzed with the main focus put on relative vorticity and vertical displacements. The responses of the biology, in terms of phytoplankton production and subduction, are presented and interpreted in the fourth section. Finally, the main results are discussed in relation to previous observational and modeling works.

\section{Model set up}

\section{a. The dynamical set up}

The idea is to simulate just a few interactive mesoscale structures with $O(1)$ Rossby number $(R o)$. In stratified rotating fluids, these structures result from the baroclinic instability of vertically sheared mean currents. Therefore, we use a classical physical context in which mesoscale and sub-mesoscale structures result from the nonlinear equilibration of an unstable baroclinic jet. A zonally periodic $\beta$-plane channel centered at $30 \mathrm{~N}$ is used. The basic state is a uniform potential vorticity zonal jet in geostrophic and hydrostatic balance (Fig. 1) resulting from the interpolation between a northern and a southern density profiles using a hyperbolic tangent law. Both profiles are homogeneous in the upper $100 \mathrm{~m}$. The mean density profile that yields a first baroclinic Rossby radius of 


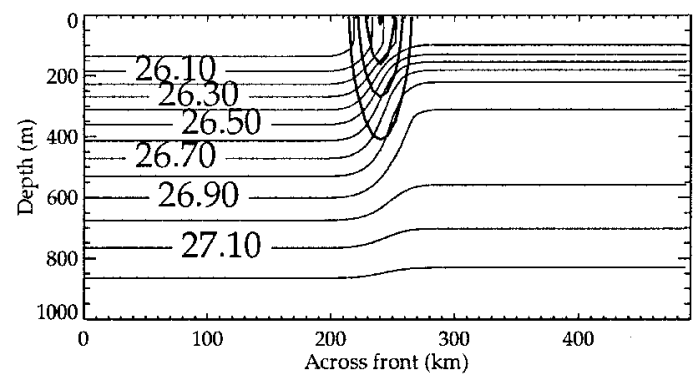

Figure 1. Initial zonal density front (light lines) and its associated geostrophic jet (heavy lines, contours every $0.2 \mathrm{~m} \mathrm{~s}^{-1}$ ).

deformation of $30 \mathrm{~km}$ is characteristic of mid-latitudes. The jet has a width of about $50 \mathrm{~km}$ and is flowing eastward with maximum velocities of $0.6 \mathrm{~m} \mathrm{~s}^{-1}$ at the surface. Relative vorticity (defined as $\zeta \equiv \partial v / \partial x-\partial u / \partial y$ with $u$ and $v$ the horizontal components of the velocity field) ranges from $0.45 f$ on the north side to $-0.45 f$ on the southern side (with $f$ the Coriolis parameter), which leads to a Rossby number $(R o \equiv \zeta / f)$ of order one. Due to the important slope of the isopycnals, and to the resulting geostrophic current shears, this baroclinic jet is unstable. The most unstable wave has a wavelength of $160 \mathrm{~km}$, a growth rate of approximately (15 days) $)^{-1}$ and is mainly captured by the first baroclinic mode (whose zero-crossing is at a depth of $500 \mathrm{~m}$ ). The initial density field is perturbed with the fastest growing unstable mode.

The domain geometry is a channel $500 \mathrm{~km}$ wide, $160 \mathrm{~km}$ long and $4000 \mathrm{~m}$ deep. The domain length is chosen to correspond to one wavelength of the most unstable baroclinic wave. The inverse energy cascade is thus artificially arrested but the direct cascade of any tracer is free to develop up to the resolution grid. It is this choice that allows just a few mesoscale structures. This set up, therefore, enables us to focus principally on the production of sub-mesoscale structures and on the interaction between these structures and the mesoscale eddies. Free-slip conditions and no heat flux are applied along solid boundary, except at the bottom where a linear friction drag is applied (equal to $4.6 \times$ $10^{-4} \mathrm{~m} \mathrm{~s}^{-1}$ ). The surface is forced with a uniform and constant penetrative solar radiation of $250 \mathrm{~W} \mathrm{~m}^{-2}$ and a radiative cooling such that the net surface heat flux is zero. This surface heat forcing makes the mixed-layer depth constant in the absence of horizontal and vertical advection. No wind forcing is included. For the sake of simplicity, a linear equation of state is assumed $(\rho=1028.5-0.1176 \times T$ with $\rho$ the density and $T$ the temperature).

In this study, we do not consider motions with frequencies larger than $f$. Within this dynamical framework, the primitive equations are the most suitable set of equations to describe the time evolution of the dynamical flow field (Gill, 1982; McWilliams et al., 1986). The ocean circulation model used is the primitive equation numerical model OPA (Madec et al., 1991; 1999) where vertical eddy coefficients are computed from an 
embedded 1.5 turbulent closure model (Blanke and Delecluse, 1993). There are 30 $z$-coordinate vertical layers, whose thicknesses vary from 10 to $20 \mathrm{~m}$ in the upper $100 \mathrm{~m}$, and increase up to $300 \mathrm{~m}$ at the bottom. Horizontal mixing of density and momentum is included through biharmonic friction terms which insure numerical stability by selectively dissipating the smallest horizontal scales of all fields.

Several experiments are performed that differ in their horizontal resolution and horizontal dissipation coefficient. Horizontal resolutions range from $20 \mathrm{~km}$ to $1.5 \mathrm{~km}$. For the simulation with a resolution of $2 \mathrm{~km}$, the dissipation coefficient is tuned to the smallest possible value to avoid numerical noise, $\left|K_{2 \mathrm{~km}}\right|=0.5 \times 10^{9} \mathrm{~m}^{4} \mathrm{~s}^{-1}$. Then, for consistency between the change in resolution and the change in dissipation, dissipation coefficients for the other resolutions are computed from $K_{2 \mathrm{~km}}$ imposing the time scale associated with the biharmonic dissipation term, $\Delta x^{4} / K_{\Delta x}$, to be constant (where $\Delta x$ is the horizontal space grid, and $K_{\Delta x}$ the dissipation coefficient for the simulation with a $\Delta x$ space grid). The time steps decrease from 15 minutes in the 20-km experiment, down to 1 minute in the $1.5 \mathrm{~km}$ experiment. Experiments last 25 days. Model outputs are daily averages.

The internal Rossby radius of deformation $\left(R_{d}=30 \mathrm{~km}\right)$ is the scale that characterizes the mesoscale structures. Representation of that scale requires at least $4-5$ grid points, and, therefore, a space grid of approximately $6-7 \mathrm{~km}$. However, we have found that increasing the numerical resolution from $6 \mathrm{~km}$ to $2 \mathrm{~km}$ significantly modifies the dynamical fields and enhances primary production. This reveals that sub-mesoscale structures, which are not well resolved when $\Delta x \geq 6 \mathrm{~km}$, have a significant influence on the dynamical and biological fields.

Within this dynamical set-up, convergence seems to be attained at $2 \mathrm{~km}$ resolution. Indeed, the results of a simulation with a $1.5 \mathrm{~km}$ resolution have been found to be very close to those with a $2 \mathrm{~km}$ resolution, in terms of the kinetic energy budgets, primary production budgets and mesoscale and submesoscale structures in physical space. Moreover, it is worthwhile to mention that, in our study, the subgrid processes (at scales smaller than $1.5 \mathrm{~km}$ ) are classically parameterized through a horizontal diffusion coefficient. This coefficient is adjusted, as usual, to allow the direct tracer cascade to work efficiently (cf. Protas et al., 1999). Using a higher numerical resolution (i.e., equal to or smaller than $1 \mathrm{~km}$ ) implies that these processes, at these small scales, need to be explicitly represented. Their correct representation requires the use of more sophisticated models, such as nonhydrostatic models. This issue is beyond the scope of this paper.

Therefore, the course of this paper mainly concerns the analysis and comparison of two numerical experiments: the $M$ (for Mesoscale) experiment with a resolution of $6 \mathrm{~km}$ and the $\mathrm{S}$ (for Sub-mesoscale) experiment with a resolution of $2 \mathrm{~km}$. Results of a Large-scale (hereafter L) experiment, corresponding to a $10 \mathrm{~km}$ resolution, will be briefly mentioned. In terms of number of grid points to represent the mesoscale eddies, this large-scale experiment corresponds to so-called eddy-permitting experiments; i.e., experiments where 
mesoscale features are described with no more than 2-3 grid points (such as in Oschlies and Garçon, 1998).

\section{b. The biological set-up}

The biological model consists of six prognostic variables expressed in terms of their nitrogen content: nitrate, ammonium, phytoplankton, zooplankton, detritus and dissolved organic matter. This model, although quite simple, is sufficiently complex within the context of this study, as we are mainly concerned with the evolution of phytoplankton. Its original feature is the explicit distinction between new production (i.e., nitrate consumption by phytoplankton, nitrate mainly being provided to the euphotic layer by dynamical processes) and regenerated production (i.e., ammonium consumption by phytoplankton, ammonium essentially being regenerated within the euphotic layer). The Eulerian time evolution of one state variable concentration $C$ is controlled by biogeochemical processes, advection and vertical diffusion:

$$
\frac{\partial C}{\partial t}=S(C)-\nabla \cdot(\mathbf{u} C)+\frac{\partial}{\partial z}\left(k_{z} \frac{\partial C}{\partial z}\right)
$$

where $\nabla \cdot()$ is the 3-D divergence operator, $\mathbf{u}$ the velocity vector and $k_{z}$ the vertical diffusion coefficient computed by the physical model. $S(C)$ is the biogeochemical source/sink term, and is fully described in the Appendix.

Numerical resolution of Eq. 1 is described in Foujols et al. (2000). The requirements of biogeochemical transport are sufficiently different from those of temperature as to provide some justification for the usage of different advection schemes and subgrid-scale parameterizations. The major requirement is positivity, and therefore the centered finite difference scheme used for the advection of temperature cannot be used. Instead, the MUSCL positive advection scheme is used, which conserves with good accuracy the extremum values and the gradients of the advected field (Van Leer, 1977; Hourdin and Armengaud, 1998). In comparison with centered differences, MUSCL is more diffusive and less dispersive (Lévy et al., 2001); therefore, no explicit horizontal diffusion is taken into account. Tests undertaken with nonzero biharmonic horizontal diffusion have revealed almost no change in the results, with the exception that the biharmonic operator generates negative tracer concentrations (that are treated as zero for the computation of the biological terms).

The initial conditions for the ecosystem are taken from the steady state solution of a one-dimensional configuration where only vertical diffusion is taken into account (see the thin line on Fig. 9). These initial conditions are representative of highly oligotrophic conditions, typical of summer conditions at mid latitudes (Fasham et al., 1985; Michaels and Knap, 1996). The nitracline and phytoplankton subsurface maxima are located at $110 \mathrm{~m}$ depth. Weak diffusive nitrate inputs within the euphotic layer supply primary production with an $f$-ratio of 0.5 at $110 \mathrm{~m}$ but rapidly decreasing to very small values above the subsurface maxima. Phytoplankton growth is nutrient limited, and any additional vertical transport of nutrient into the euphotic layer is expected to destabilize the biological 

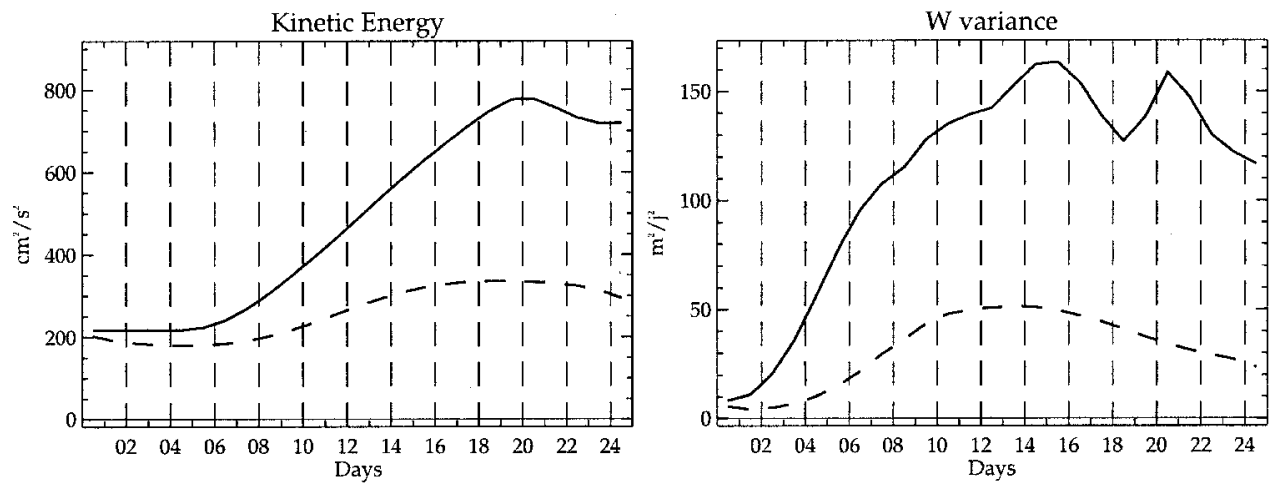

Figure 2. Basin-averaged surface kinetic energy and 0-500 $\mathrm{m}$ vertical velocity variance for the sub-mesoscale S (plain line) and the mesoscale M (broken line) experiments.

steady state by stimulating new production. Weak diffusion of the phytoplankton subsurface maxima exports some biomass below the euphotic layer.

Since the three-dimensional biological model is initialized from the one-dimensional biological steady state, there are no initial cross frontal gradients in the biogeochemical variables. Consequently, the initial nitrate field is decorrelated from the density field. This assumption is justified both within the euphotic layer, where nitrates are depleted, and below when nitrate remineralization sources have the same amplitude on both sides of the front. Such an initial nitrate distribution is also a mean to neglect the impact of the nitrate meridional variability.

\section{Results}

We first investigate the nonlinear evolution of the dynamical field and then that of the biogeochemical variables, in order to identify the dynamical processes that affect phytoplankton production and subduction and to quantify their influence.

\section{a. Dynamics}

The time evolution of the surface kinetic energy is typical of the nonlinear baroclinic instability of a zonal jet in the $\beta$-plane, for both the $\mathrm{M}$ and the $\mathrm{S}$ experiments (Fig. 2): a period of growth of the unstable waves (from days 1 to 12 approximately), associated with the transfer from mean available potential energy into kinetic energy and where linear terms dominate, is followed by a period where the dominance of the nonlinear terms (days 12 to 24 approximately) leads to the formation and ejection of mesoscale features. In the following, focus is put on the period of the simulations corresponding to a nonlinear equilibrated regime, that is a period where the kinetic energy averaged over the whole domain does not evolve much. The $w$-variance is generally a good index for the 
identification of this equilibrated nonlinear regime which, from Figure 2, occurs between days 12 and 24.

Figure 2 reveals important differences between the $M$ and the $S$ experiments: at day 24 the value is almost 3 times larger with the higher resolution. A similar ratio is found for the vertical velocity variance. In the $M$ experiment, maximum surface kinetic energy is reached around day 18 , and maximum $w$-variance around day 14. Maxima are reached two days later in the $\mathrm{S}$ experiment. Examination of the dynamical fields in the physical space yields more information about the sub-mesoscale structures, not present in the $\mathrm{M}$ experiment, that explain these differences. We first focus on relative vorticity since, from the potential vorticity conservation, relative vorticity is anticorrelated with vertical stretching, and is, therefore, a good index of vertical displacement, which is of primary importance for biological processes.

i. Relative vorticity. Relative vorticity associated with the initial frontal jet is negative on the warm side of the front (Fig. 3, day 1, red scale) and positive on the cold side (blue scale). In both experiments, during the first days, meanders develop with a distinctly meridional asymmetry characterized by a NW-SE horizontal phase tilt (Fig. 3, day 14). This asymmetry is characteristic of baroclinic instability of jets with a Rossby number of order $O$ (1) (Snyder et al., 1991). It is more emphasized in the $\mathrm{S}$ than in the M experiment. This can be seen from the shape of the vorticity contours which shows a tendency for a more pronounced NW-SE flow in the northern part of the jet whereas the flow tendency appears to be purely south or north in the southern part. This distinction reveals the better representation of the $O(1)$ ageostrophic circulation in the S experiment, even in the early part of the nonlinear regime. Relative vorticity amplitude, which ranges from $-0.8 f$ to $f$ in the $\mathrm{M}$ experiment and from $-f$ to $3 f$ in the $\mathrm{S}$ experiment, confirms and quantifies the greater importance of the ageostrophic circulation in the $\mathrm{S}$ experiment.

At day 22 the nonlinear regime is fully attained (Fig. 2) and mesoscale eddies are developed. Nonlinear dynamics of baroclinic jets with $R o=O(1)$, usually involve large, weak anticyclones that persist in the north and strong, intense cyclones that eventually degenerate in the south (see for example Snyder et al., 1991). These characteristics result from the mass and potential vorticity conservation, in the presence of a large meridional slope of the isopycnals (Fig. 4). They are somewhat observed in both experiments after meanders have broken up. In the $\mathrm{M}$ experiment, the relative vorticity field displays a well-formed anticyclonic eddy in the northern part of the domain and a strongly deformed cyclonic eddy near the center of the domain that seems to degenerate into a thin filament. The $\mathrm{S}$ experiment displays a much wider anticyclonic eddy developing on the northern side with its vorticity extremum located not in the center but on its edges. On the southern side a small, but intense and coherent, cyclonic eddy is present with its vorticity maximum located at the center.

In the $\mathrm{M}$ experiment, maximum vorticity gradients at the surface do not evolve with time, while they increase by a factor of three in the $\mathrm{S}$ experiment. In the latter experiment 

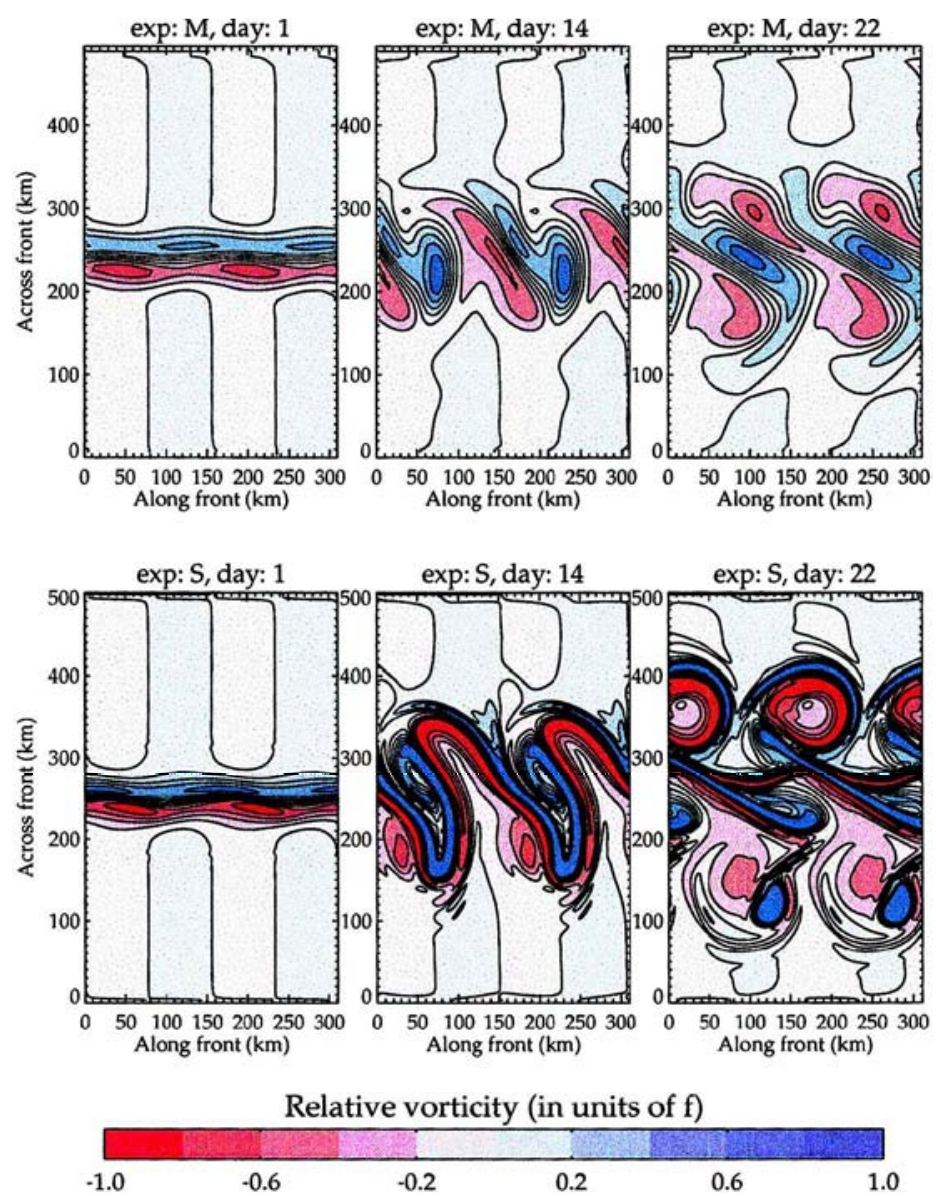

Figure 3. Surface relative vorticity for the mesoscale $\mathrm{M}$ and the sub-mesoscale $\mathrm{S}$ experiments. For clarity reasons and taking advantage of the zonal periodicity, in this figure as well as in Figures 7, 11 and 12 , the domain is artificially doubled in length in its zonal direction.

they surround sub-mesoscale structures such as the positive vorticity filament observed at day 22. One important hallmark is that strong vorticity gradients are closely related to the mesoscale eddies: the anticyclonic eddy on Figure 3 is shielded by a ring of positive vorticity with an associated strong gradient. The cyclonic eddy is also bounded by a high vorticity gradient. These gradients around the eddies are known to act as dynamical barriers that preserve coherence of the eddies and increase their life-time (Mariotti et al., 1994). As a consequence, the meridional extension of the mesoscale features is much larger in the $\mathrm{S}$ than in the $\mathrm{M}$ experiment.

The quantitative importance of the sub-mesoscale and mesoscale features for the two experiments is displayed by their relative vorticity spectra (Fig. 5). At small wavelengths $(\leq 10 \mathrm{~km})$, the enstrophy quickly decreases (with a $k^{-6}$ slope, with $k$ the wavenumber) in 


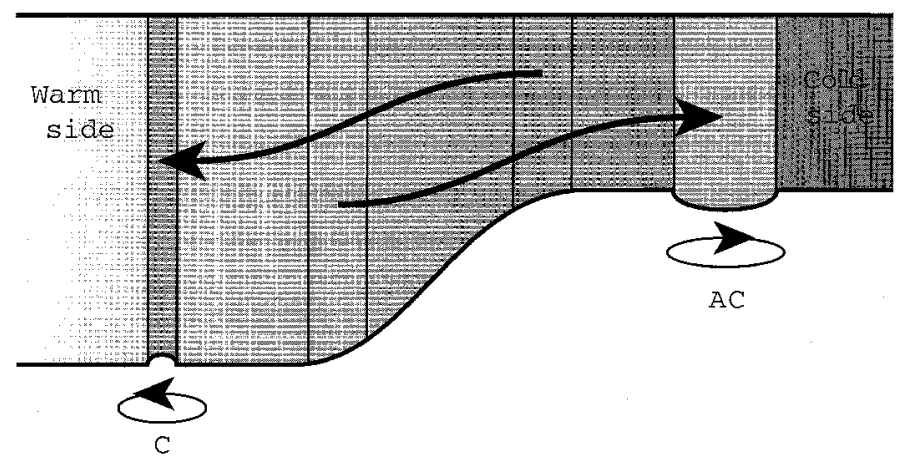

Figure 4. Schematic representation of the formation of active cyclonic (C) and anticyclonic (AC) eddies.

the $\mathrm{M}$ experiment (which reflects the dissipative effect of the biharmonic dissipation at scales smaller than $\sim 10 \mathrm{~km}$ ), whereas the enstrophy in the $S$ experiment slightly decreases with a $k^{-1}$ slope. At larger wavelengths $(\geq 10 \mathrm{~km})$, the enstrophy is also higher in the $\mathrm{S}$ experiment. These larger wavelengths are related to the scales of the eddies, that are more energetic in the $S$ experiment due to the presence of the dynamical barriers. Thus, in the $S$ experiment, the emergence of the sub-mesoscale dynamics in turn reinforces the mesoscale dynamics.

ii. Vertical velocities. We have already noted that the vertical velocity variance is almost three times larger in the $\mathrm{S}$ than in the M experiment (Fig. 2). Locally, $w$-maxima at $100 \mathrm{~m}$ depth attain $20 \mathrm{~m} \mathrm{~d}^{-1}$ in the $\mathrm{M}$ experiment, but can reach $100 \mathrm{~m} \mathrm{~d}^{-1}$ in the $\mathrm{S}$ experiment.

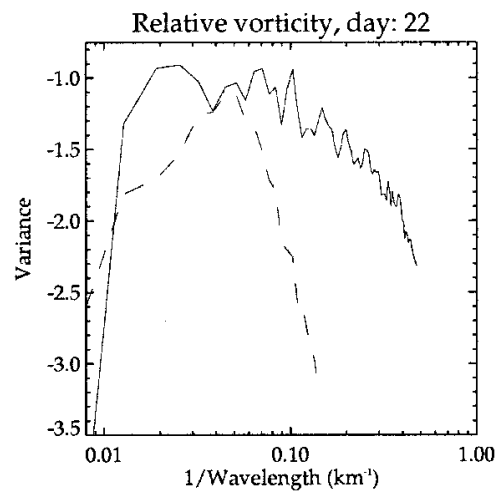

Figure 5. Enstrophy spectra at day 22, for the sub-mesoscale S (plain line) and the mesoscale $\mathrm{M}$ (broken line) experiments. 


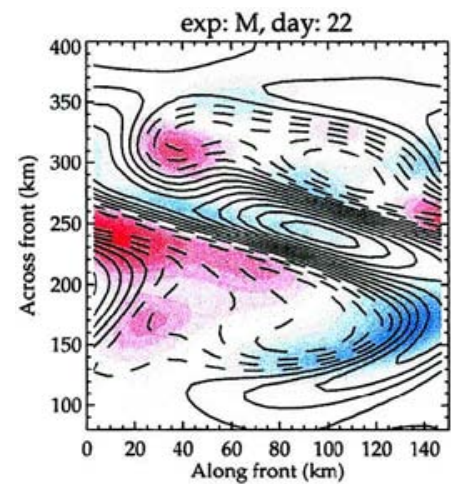

Vertical velocity $(\mathrm{m} / \mathrm{d})$

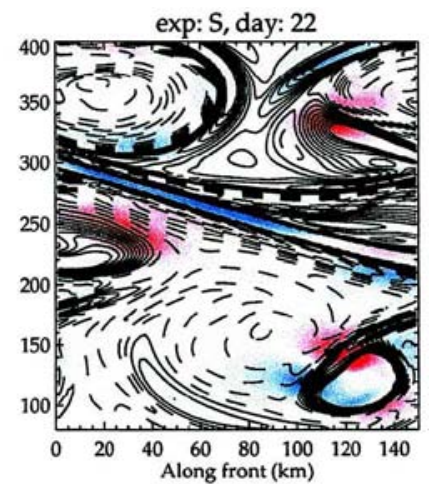

Vertical velocity $(\mathrm{m} / \mathrm{d})$

$-15 .-10 . \quad-5 . \quad 0 . \quad 5 . \quad 10.15$.

$-40 . \quad-27 . \quad-13.0$. 0.13 .27 .40$.

Figure 6. Zoom on the $100 \mathrm{~m}$-depth $w$-field at day 22 in the mesoscale $\mathrm{M}$ and the sub-mesoscale $\mathrm{S}$ experiment. Vertical velocities are positive upward, and negative downward. Superimposed black contours are those of relative vorticity, plain lines are for positive vorticity contours and dashed lines for negative vorticity contours. In the $S$ experiment, a particularly spectacular dipolar $w$-structure is related with the central filament: on the upper part of the filament, where gradients are growing, $w$ is negative on the positive vorticity side and positive on the negative vorticity side. Signs are reversed on the lower end of the filament, where gradients are decreasing.

Figure 6 displays the $w$-patterns at $100 \mathrm{~m}$ depth and their relationship with the surface relative vorticity field.

In the $\mathrm{M}$ experiment $w$-patterns are mostly multipolar structures located around the eddies, within the regions of large vorticity gradients. From vertical sections (not shown) these structures extend from the surface down to $1000 \mathrm{~m}$ with their maximum at a depth of about $500 \mathrm{~m}$, which stresses the dominance of the first baroclinic mode. Such patterns, with mostly tripolar and quadripolar structures, have been rationalized by geostrophic stratified turbulence studies (see Davies-Jones, 1991; Xu, 1990 and 1992; Hua et al., 1998). They are induced by the curvature variation of the flow and the along-flow speed variation in jet streaks. From these studies it is also known that any tracer field forced by such $w$-structures is characterized by a spectrum with a $k^{-2}$ slope, i.e., by mesoscale structures much more energetic than small-scale structures (Klein et al., 1998).

Besides these multipolar $w$-structures, the $\mathrm{S}$ experiment also reveals the presence of much thinner and intense $w$-patterns that are absent in the M experiment (Fig. 6). These patterns are the signature of active small-scale frontal dynamics, which emphasizes the efficiency of the sub-mesoscale physics. They are closely associated with the strong vorticity gradients and are characterized by a conspicuous dipolar structure astride these gradients (as within the filament crossing from $x=0 \mathrm{~km} y=300 \mathrm{~km}$ to $x=150 \mathrm{~km} y=$ $200 \mathrm{~km}$ ), which is a characteristic of frontogenesis and frontolysis processes (DaviesJones, 1991; Spall, 1997). They induce a strong distortion of the "usual" quadripolar 
patterns around the eddies, which is mostly apparent in the ring of positive vorticity around the anticyclonic eddy (At $x=110 \mathrm{~km}$ and $y=375 \mathrm{~km}$ ). Since strong vorticity gradients can only be formed in strain-dominated regions (Lapeyre et al., 1999), the dipolar $w$-patterns are mostly located within these regions, which are the regions where strong gradients of any tracer are produced by the horizontal velocity field. As a result, any tracer field forced by such $w$-patterns should exhibit only small-scale structures (Lapeyre et al., 2001).

Vertical sections (not shown) reveal that these thin and intense $w$-patterns are dominant in the first $200 \mathrm{~m}$, whereas the larger scales (i.e., tripolar and quadripolar) $w$-structures prevail at larger depths. Spectrum analysis of the $w$-field in the S experiment at different depths corroborates this depth-dependentscale partition. From this analysis, it is, therefore, expected that a tracer field forced by the $w$-field of the $\mathrm{S}$ experiment will develop filamentary structures close to the surface and larger scale structures at depths.

iii. Lagrangian trajectories. A convenient means to visualize and characterize both the horizontal redistribution of water masses and the associated vertical displacement is to compute the Lagrangian trajectories associated with the flow field. Here we consider some 20,000 floats uniformly distributed on both sides of the front and at a depth between $65 \mathrm{~m}$ and $165 \mathrm{~m}$. Trajectories of these floats are computed with the methodology described by Blanke and Raynaud (1997).

Figure 7 shows a time series of the floats' positions projected on the horizontal plane for the $\mathrm{M}$ and $\mathrm{S}$ experiments. Individual floats are characterized by their color: grey (respectively black) floats are those initially located on the warm (respectively cold) side of the front. In both experiments, the grey floats, initially confined on the warm side of the front, progressively invade the opposite side and some of them end trapped within the northern anticyclonic eddy. The inverse is true for the black floats, some of which are ultimately trapped within the southern cyclonic structure. Also, in relation with the slope of the mean isopycnal surfaces, grey floats upwell while moving north and black floats downwell while they move south (Fig. 4). After 24 days, the grey and black floats' averaged vertical displacements are much higher in the $S$ than in the $M$ experiment $(+24 \mathrm{~m} /+43 \mathrm{~m}$ for the grey floats, and $-34 \mathrm{~m} /-47 \mathrm{~m}$ for the black floats, in the M/S experiment, respectively). These differences reflect, in an integrated manner, the difference in $w$-variance. The consequence of these vertical movements is that, from the potential vorticity conservation, the grey floats that invade the cold side of the front experience a magnitude increase of their anticyclonic relative vorticity along their trajectories, while the black floats that invade the warm side of the front experience a significant increase of their cyclonic relative vorticity. As an example in the $S$ experiment, floats that are trapped in the cyclonic (resp. anticyclonic) eddy end up with a relative vorticity of $2 f$ (resp. $-f$ ), while the initial relative vorticity of floats ranges between $-0.45 f$ and $0.45 f$. On the other hand, floats that do not cross the front tend to conserve their relative vorticity. They mark satellite structures associated with strongly active mesoscale structures such as the weak anticy- 

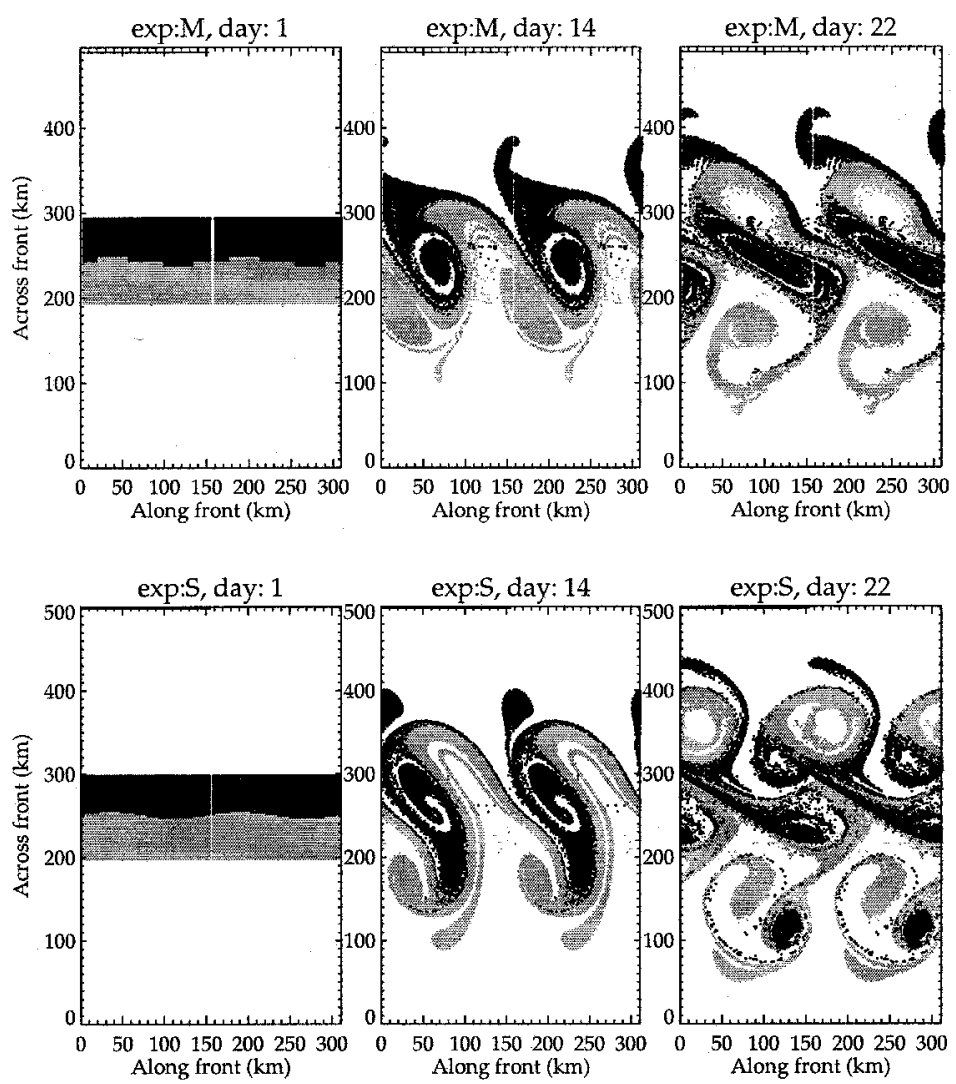

Figure 7. Lagrangian float dispersion, projected on the horizontal plane, for the mesoscale $\mathrm{M}$ and the sub-mesoscale $\mathrm{S}$ experiments.

clonic eddy in the south of the front that is associated with the energetic cyclonic eddy. These floats do not experience significant vertical displacements. Thus, comparison of Figures 3 and 7 shows a good agreement between the sign of the surface relative vorticity and the spatial distribution of grey and black floats.

\section{b. Biology}

The 4D- $(x y z t)$ variability of the biological fields is analyzed in three steps. First, quantitative analyses are performed on 1D- $(t)$ diagnostics, corresponding to the time evolution of the fields integrated over the frontal zone (from $x=0$ to $150 \mathrm{~km}$ and $y=50$ to $450 \mathrm{~km}$ ) and over the euphotic layer (taken as the first $120 \mathrm{~m}$ of the water column). Then, impacts on the vertical structure are analyzed at day 18 from 1D- $(z)$ diagnostics corresponding to the profiles horizontally averaged over the frontal zone. Finally, the driving mechanisms for phytoplankton spatial heterogeneity are analyzed using a time series of phytoplankton 2D-( $x y)$ fields integrated over and below the euphotic layer. 
a) Nitrate transport
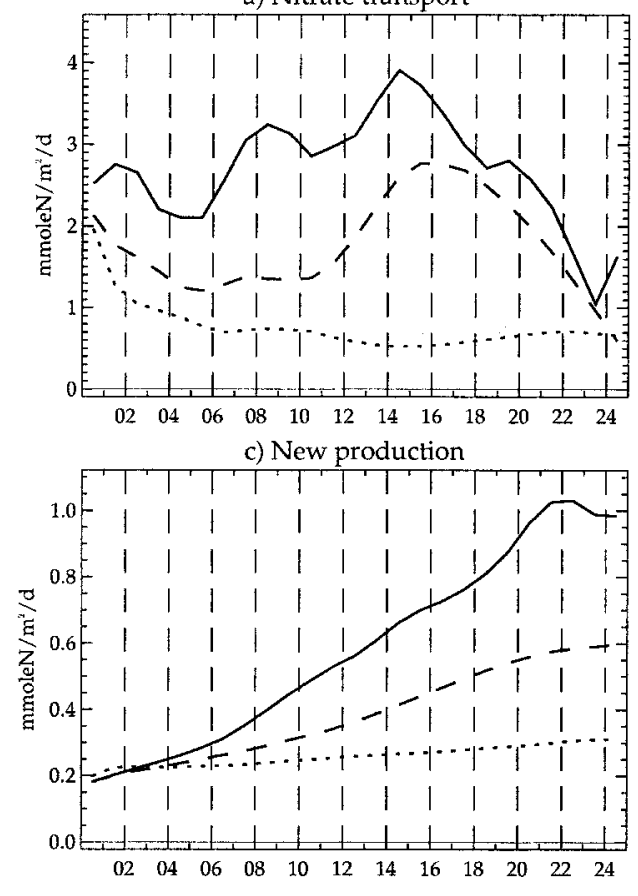

e) Nitrate

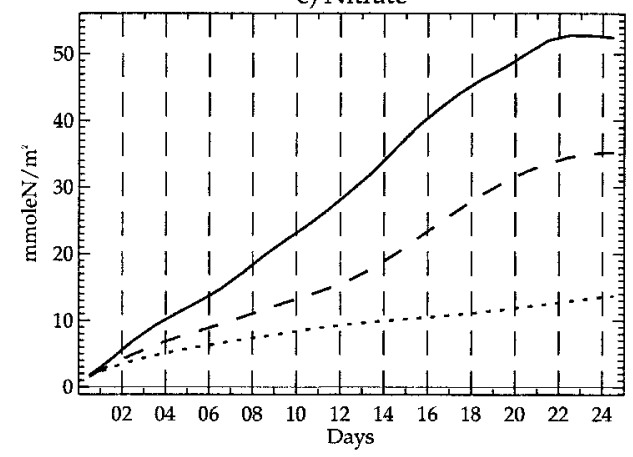

b) Phytoplankton transport

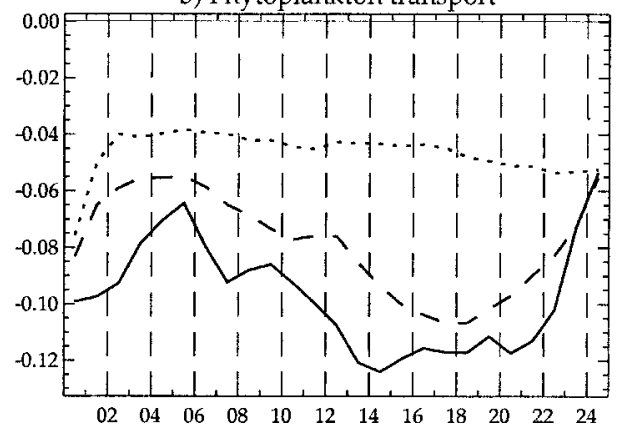

d) Regenerated production
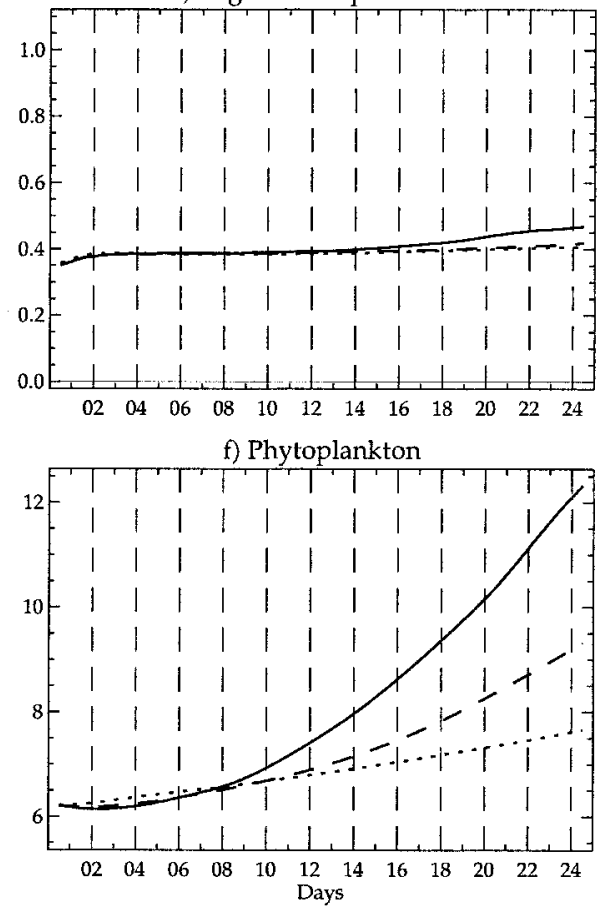

Figure 8. Time evolution of averages over the frontal area $(x=0-150 \mathrm{~km}, y=50-450 \mathrm{~km})$ and the euphotic layer $(z=0-120 \mathrm{~m})$, for the sub-mesoscale S (plain line), mesoscale M (broken line) and eddy permitting $\mathrm{L}$ (dotted line) experiments.

i. Quantitative analysis. Quantification of the influence of mesoscale and sub-mesoscale dynamics on phytoplankton production and export budgets is done on the time-evolution of the most relevant terms in Eqs. 1; that is nitrate and phytoplankton transport, new and regenerated production, nitrate and phytoplankton concentrations. These terms are integrated over the frontal area and the euphotic layer, and displayed in Figure 8 for the $S$, the $\mathrm{M}$, and the $\mathrm{L}$ experiment. In the $\mathrm{L}$ eddy-permitting experiment (not shown in details), 
Table 1. Nitrate transport (Ntr), new production (NP), total production (TP) and phytoplankton transport (Ptr) within the euphotic layer (integrated over the nonlinear period of the simulations, i.e., from days 12 to 24$)$, for the eddy-permitting(L), the mesoscale (M) and the sub-mesoscale(S) experiments. Units are $\mathrm{mmoleN} / \mathrm{m}^{2}$.

$\begin{array}{lrrrc} & \text { Ntr } & \text { NP } & \text { TP } & \text { Ptr } \\ \text { S experiment } & 35.26 & 10.70 & 16.25 & -1.40 \\ \text { M experiment } & 26.00 & 6.51 & 11.73 & -1.17 \\ \text { L experiment } & 8.00 & 3.70 & 8.84 & -0.62\end{array}$

mesoscale processes are badly represented: the front meanders without breaking into eddies, relative vorticity ranges from $-0.4 f$ to $0.4 f$ and maximum vertical velocities at $100 \mathrm{~m}$ are only $5 \mathrm{~m} \mathrm{~d}^{-1}$. Therefore, comparison between the $\mathrm{M}$ and the $\mathrm{L}$ experiments allows us to estimate the impact of mesoscale dynamics, while comparison between the $\mathrm{M}$ and the $\mathrm{S}$ experiment provides an estimate of the impact of sub-mesoscale dynamics.

During the whole duration of the experiments, nitrate transport within the euphotic layer (i.e., approximately $95 \%$ due to vertical advection and $5 \%$ due to vertical diffusion) is positive (Fig. 8a), while phytoplankton transport is negative (Fig. 8b). As expected, the primary effect of the dynamics generated by baroclinic instability is to provide nutrient and export phytoplankton to and from the euphotic layer, respectively. It should be noted that transports in the initial state, only due to vertical diffusion, are quite negligible compared with the advective transport instantaneously triggered by the instability of the jet during the first days. In the $\mathrm{M}$ and the $\mathrm{S}$ experiments, transports are maximum around day 15 , in correlation with the $w$-variance maximum. Also, due to the different amplitude of the $w$-variance between the experiments, time-averaged transports show significant deviations (Table 1). During the nonlinear phase, nitrate transport is increased by a factor $\sim 3$ between the $\mathrm{L}$ and the $\mathrm{M}$ experiment, and by another factor $\sim 1.5$ between the $\mathrm{M}$ and the $\mathrm{S}$ experiment. Similar figures are obtained for phytoplankton transport.

The increase of nitrate transport from the $\mathrm{L}$ to the $\mathrm{S}$ experiment induces a significant increase of new production (Fig. $8 \mathrm{c}$ and Table 1). However, and for all experiments, the amplitude of new production is smaller than that of nitrate transport. Also, new production maximum is attained later (at day 22 for the $\mathrm{S}$ experiment while it is still increasing after day 24 in the $\mathrm{M}$ and the $\mathrm{L}$ experiment). This shows that there is a time lag of 5 to 10 days between nitrate transport and new production. As a consequence of this time lag, the nitrate that is being brought up and not instantaneously used by photosynthesis accumulates within the euphotic layer (Fig. 8e). The accumulated nitrate will potentially be consumed by photosynthesis if later environmental conditions permit it (for instance, in the absence of wind bursts destroying the stratification). In that sense, the measure of nutrient transport within the euphotic layer can be interpreted as potential new production, in contrast with the instantaneous new production.

The net impact on the phytoplankton stock is a net increase with time, again of larger amplitude in the S experiment (Fig. 8f). Indeed, in all experiments, phytoplankton losses 
(by subduction, mortality and grazing) remain very weak compared with new production. On the contrary, zooplankton stock (not shown) remain quite steady. This is due to the long $e$-folding time of zooplankton growth in comparison with the duration of the simulation. Consequently, regenerated production also shows negligible change during the course of the simulations. Finally, in terms of total production (Table 1), mesoscale dynamics is responsible for an increase of the order of 30\%, while the increase is almost a factor of 2 when sub-mesoscale dynamics is allowed.

ii. Vertical distributions. To better understand the impact of the frontal dynamics on phytoplankton, we now focus on the vertical distribution of the most relevant terms in Eqs. 1. For that purpose, these terms are averaged on the horizontal directions, and depicted on Figure 9 at day 18. There is no qualitative variability of these averaged profiles during the course of the experiments, and day 18 is an intermediate date between the period of maximum nutrient transport and the period of maximum production.

In the $\mathrm{M}$ experiment, nitrate transport is significantly increased compared with the initial state, particularly between $50 \mathrm{~m}$ and $120 \mathrm{~m}$. In the $\mathrm{S}$ experiment, and in relation with the higher averaged upward displacement of the grey floats, the nitrate transport profile reaches depths smaller than $50 \mathrm{~m}$ (Fig. 9a). Consequently, the new production subsurface maxima is shallower in the $\mathrm{S}$ experiment $(60 \mathrm{~m})$ than in the $\mathrm{M}$ experiment $(70 \mathrm{~m})$, and in the $\mathrm{M}$ experiment than in the initial state $(110 \mathrm{~m})$.

As mentioned in the previous section, there is a time shift between nitrate transport and new production, and at day 18 nitrate transport still largely exceeds new production. However, comparison of Figure 9a and 9c reveals that this time shift diminishes with shallower depth. Indeed, in the $\mathrm{S}$ experiment and above $50 \mathrm{~m}$, new production and nitrate transport are equal, and there is no nitrate accumulation (Fig. 9e); whereas at $100 \mathrm{~m}$, new production is about 10 times smaller than nitrate transport. The depth variation of the time shift amplitude is clearly related with that of phytoplankton growth rate. Typically, due to light limitation, growth rates are of the order of $(10 \text { days })^{-1}$ at $100 \mathrm{~m}$ depth, and $(3 \text { days })^{-1}$ at $50 \mathrm{~m}$ depth. Hence, nitrate transports that reach shallow depth are utilized very efficiently by photosynthesis, and significantly increase the instantaneous new production budget (Fig. 9c).

For both experiments, there is a strong negative phytoplankton transport term (Fig. 9b). Again, this term has a wider profile and a larger amplitude in the S experiment. Below the euphotic layer, positive transport reveals the subduction of phytoplankton. Closer to the surface, positive transport is due to vertical mixing within the mixed layer.

The increase of new production above $100 \mathrm{~m}$, together with the increase of subduction below $100 \mathrm{~m}$ significantly modifies the averaged phytoplankton profile compared with the initial state (Fig. 9f). On average and due to these two effects, the subsurface maxima is much wider in the two directions (up and down). The result is even more dramatic in the $\mathrm{S}$ experiment, where vertical displacements have a larger amplitude. 
a) Nitrate transport

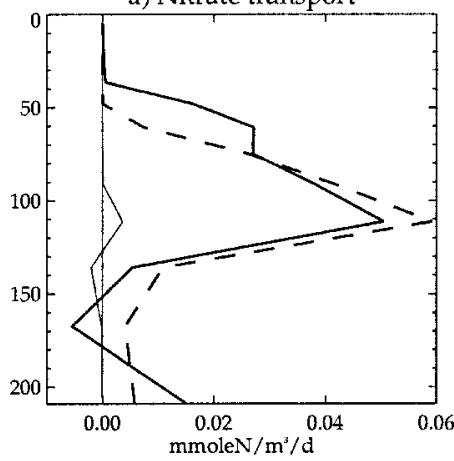

c) New production

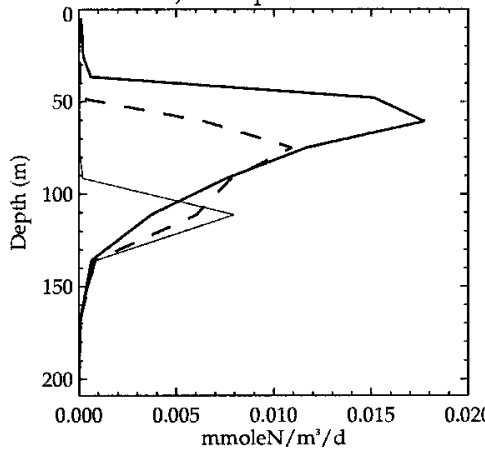

e) Nitrate

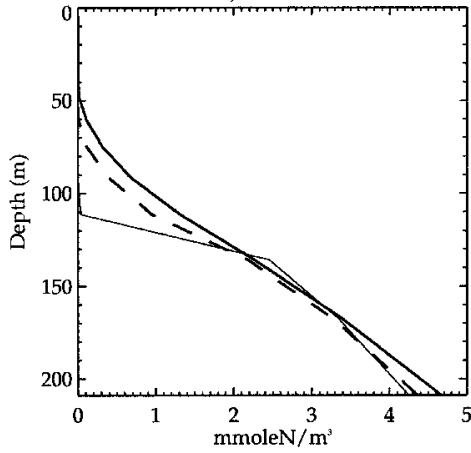

b) Phytoplankton transport

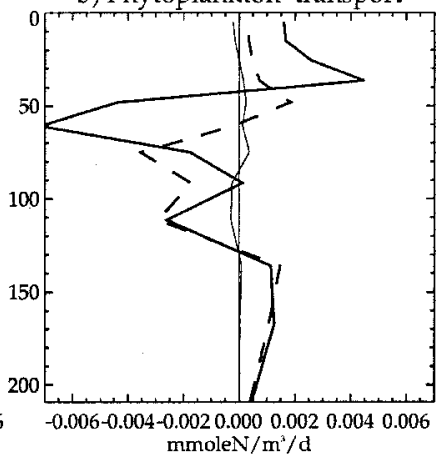

d) Regenerated production

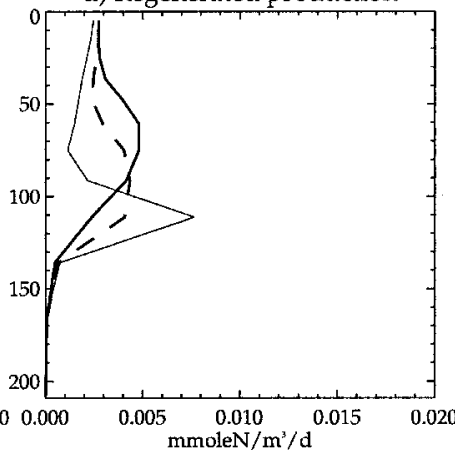

f) Phytoplankton

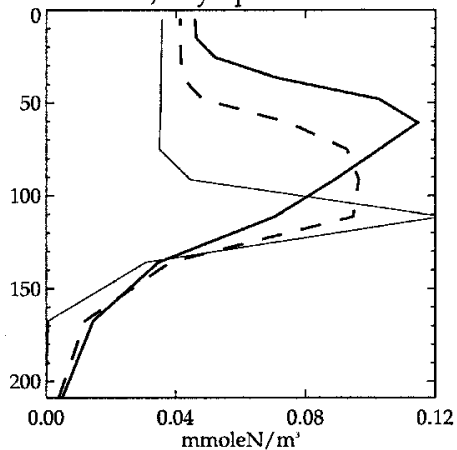

Figure 9. Profiles at day 18 (averaged over the frontal area, $x=0-150 \mathrm{~km}, y=50-450 \mathrm{~km}$ ), for the sub-mesoscale S (plain line) and the mesoscale M (broken line) experiments. The thinner line corresponds to the initial (steady) state.

iii. Driving mechanisms for biogeochemical spatial heterogeneity. Spatial heterogeneity of phytoplankton is analyzed after depth integration, within and below the euphotic layer. A common feature of both experiments is that new production is mostly found within anticyclonic vorticity regions (Fig. 10 and Fig. 3). In such an oligotrophic environment, phytoplankton patterns in the euphotic layer result from new production and from the time 

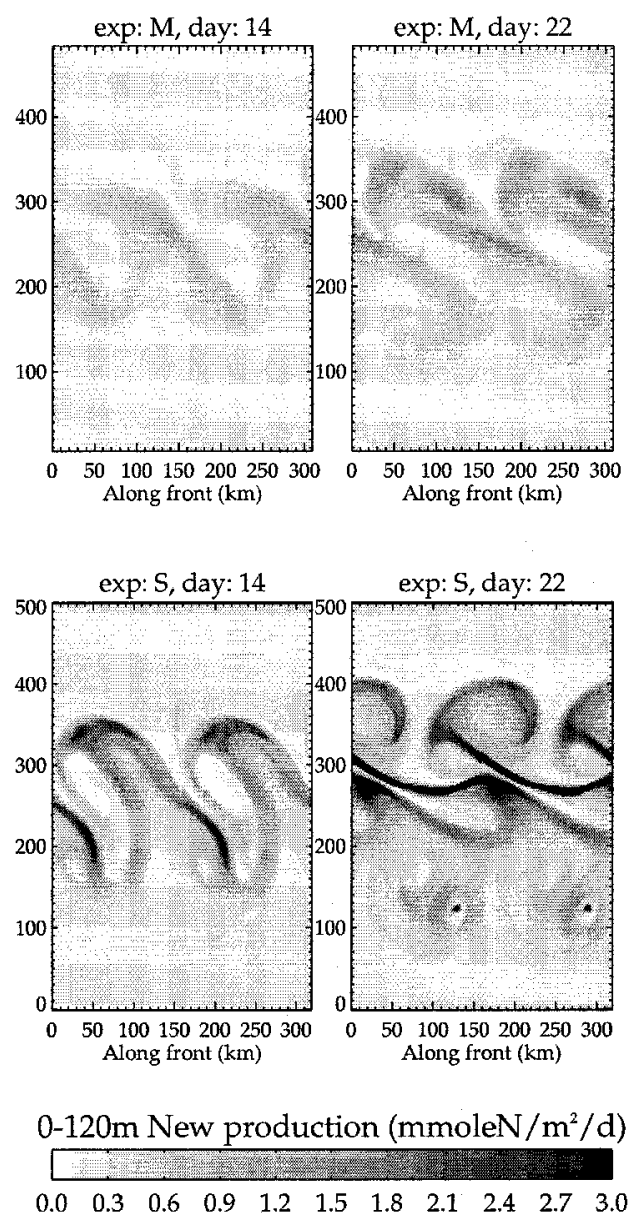

Figure 10. New production integrated over the euphotic layer $(z=0-120 \mathrm{~m})$ for the mesoscale $\mathrm{M}$ and the sub-mesoscale $\mathrm{S}$ experiments.

lag associated with the biological response. The comparison of Figure 11 and Figure 3 shows that, as for new production, phytoplankton is found mostly within anticyclonic regions. It also shows that phytoplankton maxima are decorrelated from those of NP. This decorrelation is due to the transport of phytoplankton during the biological response time lag. Correspondingly, below the euphotic layer, the subducted biomass is mostly found within cyclonic regions (Fig. 12 and Fig. 3).

The major difference is that phytoplankton patterns in the $\mathrm{S}$ experiment are mostly small-scale features, well correlated with the small-scale vorticity patterns, whose width does not exceed $20 \mathrm{~km}$, and that are nonexistent in the $\mathrm{M}$ experiment. For instance at day 22 in the S experiment, regions of high phytoplankton (Fig. 11) are principally concentrated at the edges of the anticyclonic eddy, in the anticyclonic area surrounding the 

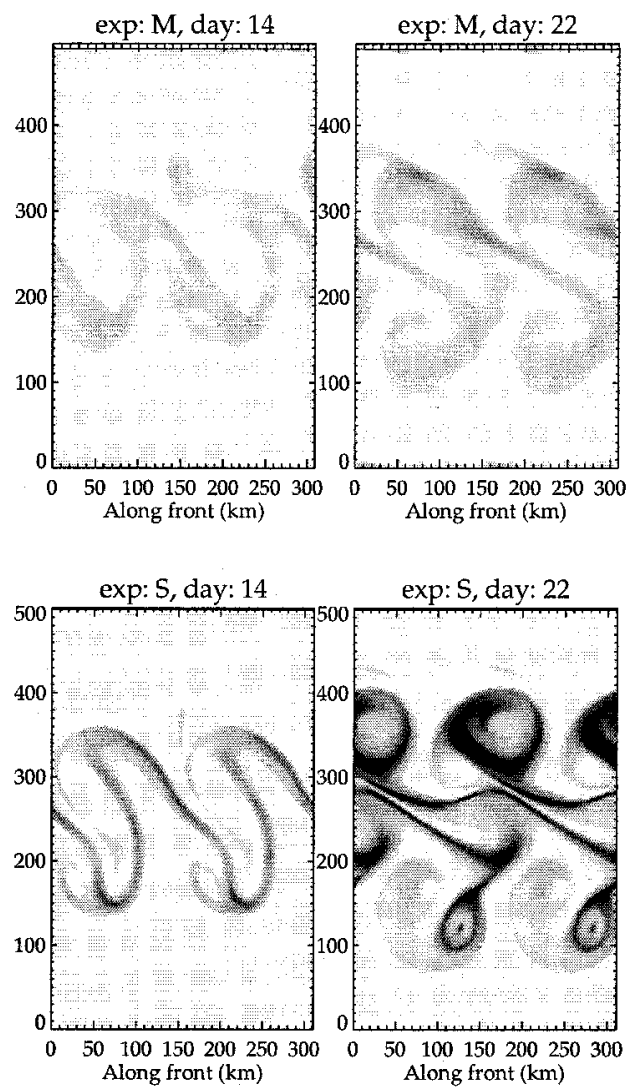

\section{0-120m Phytoplankton (mmoleN $/ \mathrm{m}^{2}$ )}

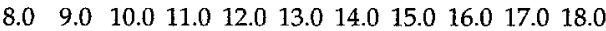

Figure 11. Phytoplankton biomass within the euphotic layer $(z=0-120 \mathrm{~m})$ for the mesoscale $\mathrm{M}$ and the sub-mesoscale $\mathrm{S}$ experiments.

cyclonic eddy and along the thin negative vorticity filaments. In the $\mathrm{M}$ experiment, phytoplankton is concentrated within the anticyclonic eddy and within the wider $(\approx 40 \mathrm{~km})$ anticyclonic filament.

At mesoscales, the distribution of new production and subduction (and of phytoplankton within and below the euphotic layer) within specific vorticity regions results from the phase relationship between the mean vertical advection and the relative vorticity evolution. During the baroclinic instability adjustment process and because of the strong mean isopycnals slope, warm water with negative relative vorticity moves northward and upward (as the grey floats) and cold water with positive relative vorticity moves southward and downward (as the black floats). As mentioned before, nonlinear dynamics and conserva- 

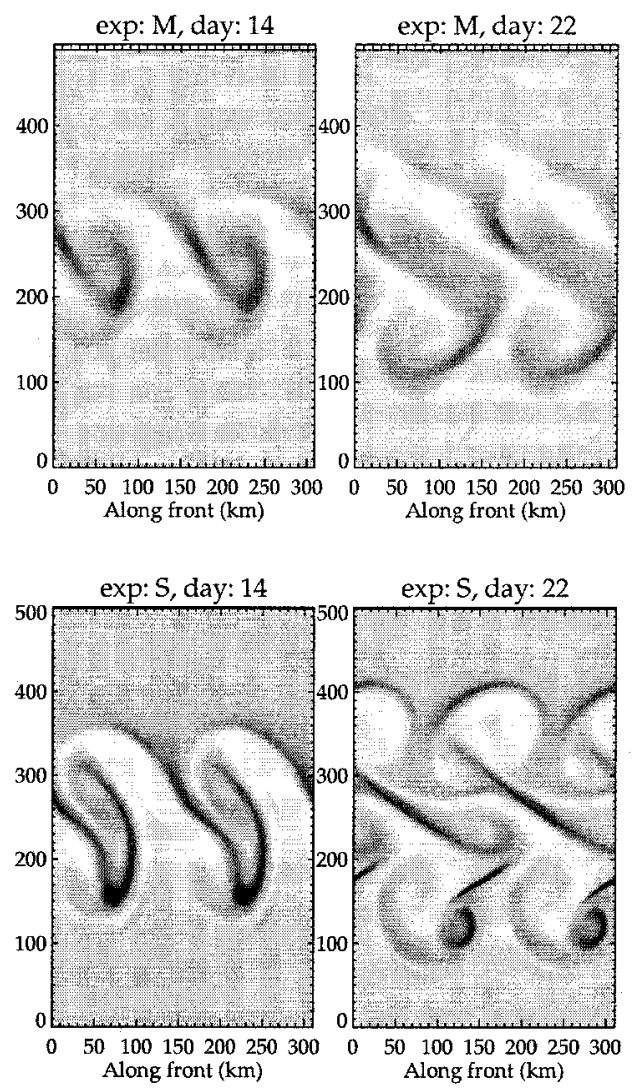

120-240m Phytoplankton $\left(\mathrm{mmoleN} / \mathrm{m}^{2}\right)$

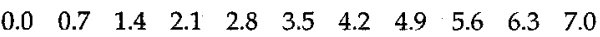

Figure 12. Phytoplankton biomass below the euphotic layer $(z=120-240 \mathrm{~m})$ for the mesoscale $\mathrm{M}$ and the sub-mesoscale $\mathrm{S}$ experiments.

tion of potential vorticity and mass ultimately lead to large and weak anticyclones in the north and small and strong cyclones in the south. The consequence is that cold cyclonic eddies, although with locally doming isopycnals at their center, are stretched downward with the result of small local nitrate upward input at a given depth. On the contrary warm anticyclonic eddies, although with locally downward isopycnals at their center, are strongly squeezed upward with the result of a significant net local nitrate input at a given depth. In other words, trajectories of grey-floats (closely associated with a negative relative vorticity as mentioned before) are preferential routes for upward nitrate supply. While they raise, nitrate is progressively converted into phytoplankton through photosynthesis. Similarly, trajectories of black-floats (associated with a positive relative vorticity) are preferential routes for phytoplankton subduction. 

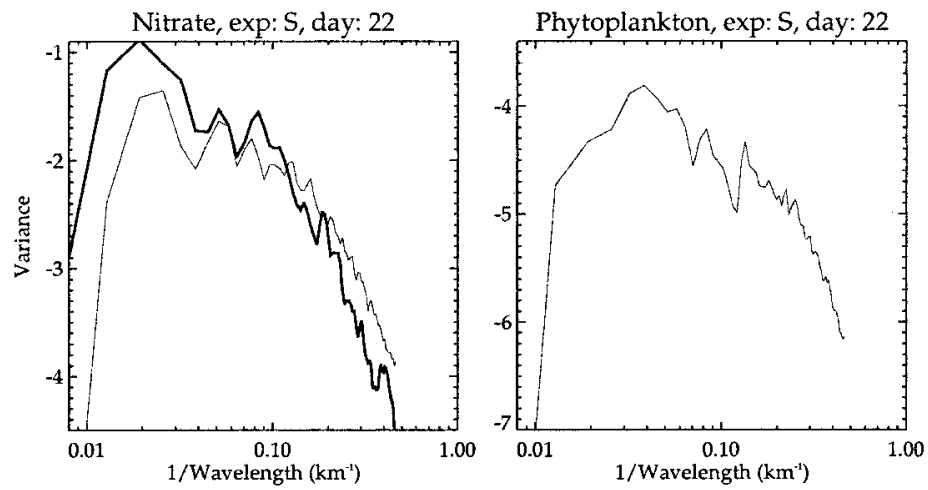

Figure 13. Spectra at day 22 in the $\mathrm{S}$ experiment of (a) nitrate concentration at $130 \mathrm{~m}$ (light line) and $550 \mathrm{~m}$ (heavy line) and (b) phytoplankton concentration at $20 \mathrm{~m}$.

The appearance of phytoplankton sub-mesoscale features in the S experiment results from the phase relationship between the bipolar $w$-patterns and the strain-dominated areas (i.e., vertical advection occurring in areas where horizontal stirring is significant). As these specific $w$-patterns extend from the surface down to $200 \mathrm{~m}$ (due to frontogenesis and frontolysis processes), they have an impact on phytoplankton distribution above and below the euphotic layer, as shown by the depth-integrated fields on Figure 11 and Figure 12. In the case of upward $w$, the associated horizontal stirring acts on water parcels where nitrate is being progressively converted into phytoplankton, with the consequence that both nitrate and phytoplankton (and therefore new production) fields show sub-mesoscale structures.

The production of nitrate sub-mesoscale structures in the upper layers is displayed by Figure 13a, which shows that the nitrate spectrum slope is much flatter at $130 \mathrm{~m}\left(k^{-1.5}\right)$ than that at $500 \mathrm{~m}\left(k^{-3}\right)$. As mentioned in Section 3a(ii), these different slopes result from the different $w$-features that drive the nitrate distributions at those two depths: quadripolar at $500 \mathrm{~m}$ and bipolar at $130 \mathrm{~m}$. Therefore, within the euphotic layer, nitrate is mainly introduced at small scales and within regions of intense horizontal stirring. Since the $w$-cores at $500 \mathrm{~m}$ and those at $120 \mathrm{~m}$ are usually located in the same strain-dominated areas (Hua et al., 1998), we believe that the $w$-cores at $120 \mathrm{~m}$ should relay the effects of those at $500 \mathrm{~m}$ in the injection of nitrates from deeper to the surface layers. Note that a quantitative rationalization of the phase relationship between these $w$-cores still requires additional work. In the present study, the small-scale phytoplankton features do not result from a direct horizontal cascade, during the photosynthesis processes, of nitrate injected at much larger scales (as suggested by Abraham, 1998) but from specific small-scale nitrate injection in strain-dominated areas. This is confirmed by the phytoplankton spectra close to the surface (Fig. 13b) which has a slope similar to that of nitrate just below the euphotic layer. 


\section{Discussion}

\section{a. Quantitative aspects}

The impact of dynamical processes on primary production estimated in this study emphasizes and enlarges the results obtained by previous modeling studies that focused on specific regions where the dynamics involve energetic mesoscale eddies. Indeed these studies already revealed that, in oligotrophic conditions, primary production can be increased by 10 to $30 \%$ when mesoscale processes are accounted for (Oschlies and Garçon, 1998; Spall and Richards, 2000; Mahadevan and Archer, 2000). The results of our process study confirm the important impact of the mesoscale physics on primary production (a $30 \%$ increase for the $\mathrm{M}$ experiment). But mostly it reveals an additional stronger impact of the submesoscale physics (a 100\% for the S experiment).

Taking into account this submesoscale physics requires the use of a horizontal numerical resolution at least equal to $\frac{1}{15}$ of the Rossby radius of deformation of the dominant vertical normal mode. Such resolution is much higher than that used in Oschlies and Garçon (1998) (2/5) and in Mahadevan and Archer (2000) (1/4). So our results suggest that the impact of the eddies and their nonlinear interactions displayed by Oschlies and Garçon (1998) and Mahadevan and Archer (2000) might be significantly increased if they used a higher resolution.

Nevertheless, the new production amplitude found in this study is within the range provided by observations in oligotrophic regions. For instance, new production estimates for the Sargasso Sea vary from 0.1 to $0.7 \mathrm{moleN} / \mathrm{m}^{2} / \mathrm{y}$ depending on the measuring method (Siegel et al., 1999). Table 1 shows that our NP estimates vary from 8 to $16 \mathrm{mmoleN} / \mathrm{m}^{2}$ / 12 days, which yields to $0.25 \mathrm{moleN} / \mathrm{m}^{2} / \mathrm{y}$ for the L experiment to $0.5 \mathrm{moleN} / \mathrm{m}^{2} / \mathrm{y}$ for the $\mathrm{S}$ experiment when extrapolated over a one-year period.

\section{b. Relationships between new production and vorticity}

A vertical section of nitrate across a cyclonic and an anticyclonic eddy respectively (Fig. 14) reveals that, in the $\mathrm{M}$ experiment, nitrate is more abundant within the anticyclonic than within the cyclonic eddy. In the $\mathrm{S}$ experiment, the nitracline is raised toward the surface on the inner-border of the anticyclonic eddy and also on the outer-edge of the cyclonic eddy, where anticyclonic vorticity is strong (Fig. 3). Within the cyclonic eddy, the doming of the nitracline at the center is strongly counter-balanced by its averaged deepening.

We have found it difficult to confront these results with in-situ observations. Indeed Yentsh and Phinney (1985) and McGillicuddy et al. (1998) found that the doming of the isopycnals in cyclonic eddies is associated with the doming of the nitracline, and therefore that cyclonic eddies are more productive than anticyclonic ones. These observations seem to challenge our results. On the other hand, Hitchcock et al. (1993), during a series of transects across the Gulf Stream, found a maximum of chlorophyll located at the periphery of a warm core ring (their Fig. 3). Strass (1992), using a towed undulating vehicle in the open North Atlantic during summer reveals patches of high chlorophyll concentration of 

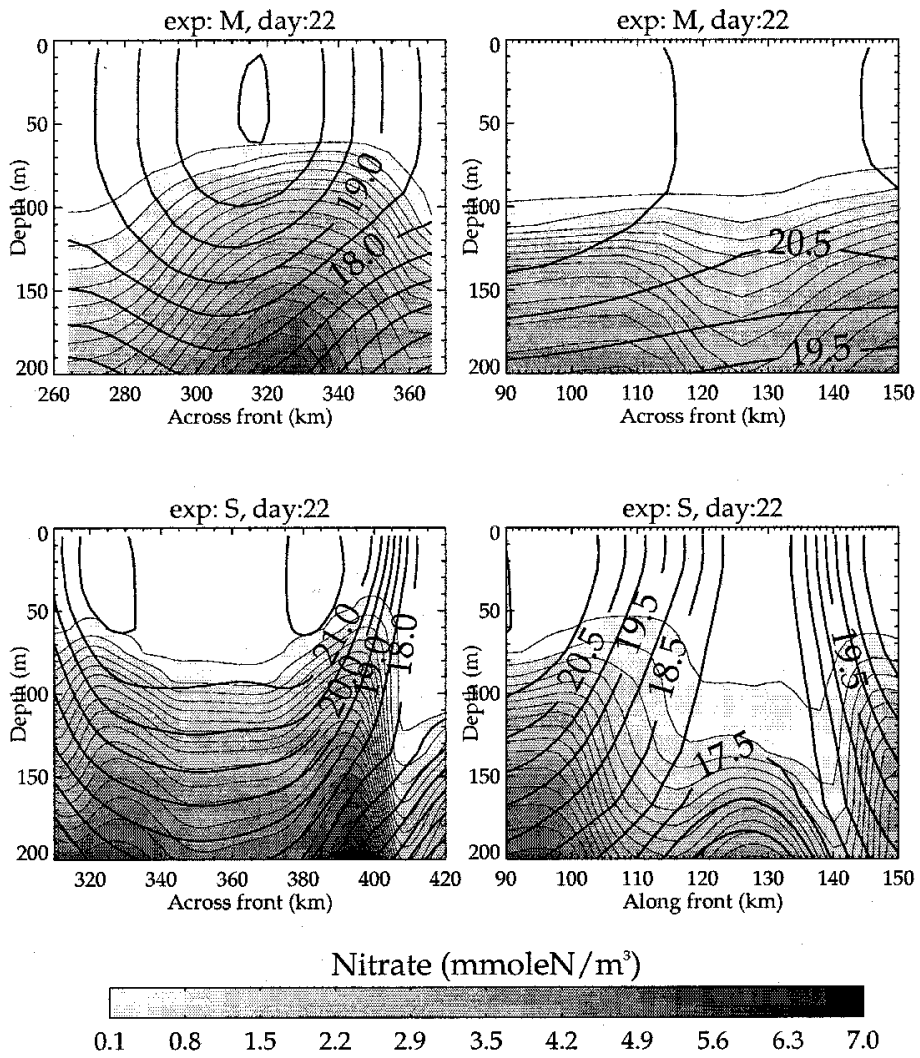

Figure 14. Vertical sections of temperature and nitrate at day 22, across an anticyclone (left figures) and a cyclone (right figures) in the mesoscale $\mathrm{M}$ and the sub-mesoscale $\mathrm{S}$ experiments.

scales $10-20 \mathrm{~km}$. These patches at the warm sides of temperature front are regions of anticyclonic vorticity. The recent observations of Perez et al. (2001), during a summer oceanographic cruise in the Azores front region, identify a warm anticyclonic eddy whose $\Theta / S$ characteristics are similar to those found in the south side of the front. Similarly, they found a cold cyclonic eddy, whose waters in the core do not come from below by upwelling, but has the characteristics of waters from the north side of the front. Furthermore, they locate with good accuracy maximum chlorophyll concentrations on the south side of the front (their Fig. 11, T1), and at the border of an anticyclonic eddy (their Fig. 11, T2). They found no clear evidence of biological activity enhancement in the cold cyclonic eddy (their Fig. 13, T4). These observations appear to confirm our results.

We believe that a significant part of the discrepancies of the in-situ observations could be explained in terms of the nitrate distribution relative to the density field. Indeed there is no specific reason for the existence of an exact relationship between the nitrate and the 
density (as traditionally assumed) especially in the surface layers of the ocean. Sources and sinks of density differ from those of nitrate. Then the nitrate field should differ from that of the density and in particular should be characterized by more energetic small-scale features. More precisely, it was found in Klein et al. (1998) that when the large-scale tracer field involves isosurfaces more horizontal than the large-scale density field, the perturbated tracer field is characterized by a much less steep spectrum slope. Furthermore, larger tracer concentrations are found in anticyclonic eddies than in cyclonic ones. The large-scale nitrate field used as an initial condition complies with this configuration, which may explain our results. However, a more thorough study is needed to rationalize this explanation.

\section{c. Phytoplankton patchiness}

As mentioned in the Introduction, phytoplankton patchiness within the euphotic layer at scales smaller than the Rossby radius of deformation is well evidenced by satellite imagery (see for example Denman and Abbott, 1994). The sources of the patchiness is usually attributed to horizontal stirring by the mesoscale eddy field, diffusive mixing and biological processes (Denman and Platt, 1976; Washburn et al., 1998; Martin, 2000). Production of small-scale filaments of tracers in the ocean by horizontal stirring has been evidenced by in-situ experiments, such as NATRE (Ledwell et al., 1993) and SOIREE (Abraham et al., 2000). To rationalize plankton patchiness, Abraham (1998) proposed an elegant and convincing scenario based on the production of smaller and smaller tracer scales by mesoscale eddies, which is the classical direct tracer cascade. Nutrients injected at large scales within the euphotic layer are subsequently affected by this cascade process that occurs at a time scale of the order of 10 days in the ocean (Klein and Hua, 1990). Because the $e$-folding time of the phytoplankton growth rate is usually smaller than the cascade time scale, the spatial variability of phytoplankton involves more energetic small scales than nutrients. In other words, the phytoplankton spectrum slope is less steep than that of nutrients. The same conclusion applies for zooplankton with respect to phytoplankton. Thus the spatial variability of the successive biological populations reflect the different phases of the cascade process. The present study, which takes into account the spatial variability of vertical velocity at meso and sub-mesoscales, provides a somewhat different scenario. The nutrient injection induced by the mesoscale and sub-mesoscale physics within the euphotic layer mostly occurs at small scales in regions dominated by strain, which directly leads to sub-mesoscale nutrient and phytoplankton variability.

In the ocean, it is likely that these two scenarios are encountered. Indeed our scenario should occur in the absence of strong wind forcing; i.e., when the mixed layer is not really active. But a strong wind burst, which has the effect of deepening the mixed-layer, should induce a nutrient injection within the euphotic layer at large scales. In this case, the scenario proposed by Abraham (1998) is the most relevant. From a biogeochemical perspective these two scenarios have, however, different implications. When phytoplankton patchiness is mainly the result of the stirring by 2D-turbulence of nutrient patterns 
injected at large scales (Abraham, 1998), estimation of a new production budget is somehow easier to quantify. On the other hand, the scenario proposed by the present work, based on nutrient injection at small scales, makes estimation of new production from low resolution data and/or model more difficult.

\section{Conclusion}

This study has focused on the impact of small-scale, or sub-mesoscale, physics on new production and phytoplankton subduction budgets in oligotrophic regimes. Results from numerical experiments designed to understand this impact reveal that the sub-mesoscale physics is responsible for more than $\frac{1}{3}$ of the larger-scale new production and phytoplankton subduction budgets. This shows that high spatial resolution is required to estimate these budgets, from observations or numerically.

The increase of new production is due to the significant enhancement of nutrient transport from the deeper layers within the surface layers, by the more energetic dynamical field. However, this injection enhancement is essentially driven, not by the vertical velocity field associated with the mesoscale dynamics (whose maximum is at $500 \mathrm{~m}$ ), but by the vertical velocity field associated with the strong small-scale density and vorticity gradients located near the surface between and around the eddies. Thus, nutrient injection occurs at small scales in specific regions where the horizontal stirring is strong. The consequence is that the phytoplankton field essentially displays small-scale features. The same dynamical features characterize the phytoplankton subduction in the deeper layers. Another important result is the strong relationship between new production, phytoplankton subduction and relative vorticity, in the absence of wind forcing and during the formation of eddies, that persists when mostly small-scale features of phytoplankton are present.

This study should be considered as a first attempt to examine the impact of small-scale physics embedded in a mesoscale eddy field onto the ocean biology. It has several limitations which should be addressed in the near future because of the stimulating results already obtained. First, more confidence about the present results could be obtained with numerical simulations extended to larger spatial domains in order to better represent both the inverse energy cascade and the direct enstrophy cascade. This should produce more robust statistics about the respective role of mesoscale and sub-mesoscale physics and allow for direct comparison with statistics obtained from satellite data. Second, simulations should also be extended to longer times scales. This should enable us to take into account the nonlinear interactions between phytoplankton and zooplankton, and the ageing of the ecosystem.

Another important direction to explore is the effects of a wind-forcing. We have already mentioned that a strong wind forcing producing a significant mixed layer deepening can induce a large-scale nutrient injection. In that situation the scenario proposed by Abraham (1998) should be relevant. What we have in mind concerns another situation where the wind forced mixed-layer dynamics does not produce significant mixed-layer deepening 
but, through nonlinear Ekman pumping, strongly enhances the small-scale frontal dynamics and, therefore, should reinforce the corresponding injection of nutrients. Such nonlinear interactions are now well documented (see for example Lee et al., 1994; Hart, 2000; Blumen, 2000), which should help to understand their consequences on phytoplankton production.

Acknowledgments. We thank two anonymous reviewers for their stimulating questions. We also thank G. Madec and L. Memery for helpful discussions. Funding for this study was provided by the Ministère de la Recherche (through the ACI program) and the CNRS. The experiments were carried out on the NEC SX-5 of the IDRIS center. We have benefited from the code developmentscarried out by the IPSL, and particularly from the work and efficiency of M.-A. Foujols. Last but not least, this work has greatly benefited from the diagnostical tools developed by Sebastien Masson, and from his kind assistance.

\section{APPENDIX}

\section{Description of the biological model}

The biological model consists of six prognostic variables expressed in terms of their nitrogen content: nitrate $\left(\mathrm{NO}_{3}\right)$, ammonium $\left(\mathrm{NH}_{4}\right)$, phytoplankton $(P)$, zooplankton $(Z)$, detritus $(D)$ and dissolved organic matter $(D O M) . S(C)$ is the total biogeochemical source/sink term for each tracer $C$ (Eq. 1). Within the first twelve vertical layer (corresponding to approximately $200 \mathrm{~m}$ ), the biogeochemical model can be formulated as (with parameter values in Table 2):

$$
\begin{gathered}
S\left(\mathrm{NO}_{3}\right)=-\mu_{p} L_{I} L_{\mathrm{NO}_{3}} P+\mu_{n} \mathrm{NH}_{4} \\
S\left(\mathrm{NH}_{4}\right)=-\mu_{p} L_{I} L_{\mathrm{NH}_{4}} P+f_{n}\left(\gamma \mu_{p} L_{I}\left(L_{\mathrm{NO}_{3}}+L_{\mathrm{NH}_{4}}\right) P+\mu_{z} Z+\mu_{d} D\right)-\mu_{n} \mathrm{NH}_{4} \\
S(P)=(1-\gamma) \mu_{p} L_{I}\left(L_{\mathrm{NO}_{3}}+L_{\mathrm{NH}_{4}}\right) P-G_{p}-m_{p} P \\
S(Z)=a_{z}\left(G_{p}+G_{d}\right)-m_{z} Z^{2}-\mu_{z} Z \\
S(D)=\left(1-a_{z}\right)\left(G_{p}+G_{d}\right)+m_{p} P-G_{d}-\mu_{d} D-V_{d} \partial_{z} D \\
S(D O M)=\left(1-f_{n}\right)\left(\gamma \mu_{p} L_{I}\left(L_{\mathrm{NO}_{3}}+L_{\mathrm{NH}_{4}}\right) P+\mu_{z} Z+\mu_{d} D\right)-\mu_{d o m} D O M
\end{gathered}
$$

where the phytoplankton growth limitation terms are expressed as:

$$
\begin{gathered}
L_{I}=1-e^{-(\text {PAR/K } / \text { par })} \\
L_{\mathrm{NO}_{3}}=\frac{\mathrm{NO}_{3}}{\mathrm{NO}_{3}+K_{\mathrm{no} 3}} e^{-\psi \mathrm{NH}_{4}} \\
L_{\mathrm{NH}_{4}}=\frac{\mathrm{NH}_{4}}{\mathrm{NH}_{4}+K_{\mathrm{nh}_{4}}}
\end{gathered}
$$


Table 2. Biological parameters.

\section{Parameter name}

Nitrate limitation half-saturation value Ammonium limitation half-saturation value

Inhibition of nitrate uptake by ammonium

Light limitation half-saturation value

Phytoplankton maximal growth rate

Phytoplankton exudation rate

Phytoplankton mortality rate

Grazing half-saturation value

Zooplankton maximal grazing rate

Assimilated food fraction by zooplankton

Zooplankton excretion rate

Zooplankton mortality rate

Nitrification rate

DOM breakdown rate

ammonium/DOM redistribution ratio

Detritus sedimentation speed

Detritus remineralization rate

Remineralization rate at depth
Symbol

$K_{\mathrm{no}_{3}}$
$K_{\mathrm{nh}_{4}}$
$\psi$
$K_{p a r}$
$\mu_{p}$
$\gamma$
$m_{p}$
$K_{z}$
$g_{z}$
$a_{z}$
$\mu_{z}$
$m_{z}$
$\mu_{n}$
$\mu_{d o m}$
$f_{n}$
$V_{d}$
$\mu_{d}$
$\tau_{r}$

Value

Unit

0.01

1.5

20.

$2.3110^{-5}$

0.05

$5.8010^{-7}$

0.2

$2.3110^{-6}$

0.7

$2.3110^{-7} \quad \mathrm{~s}^{-1}$

$2.3110^{-6}$

$5.8010^{-7}$

$3.8610^{-7}$

0.75

$1.1610^{-5}$

$1.1610^{-6}$

$5.8010^{-7}$

mmole $\mathrm{m}^{-3}$

mmole $\mathrm{m}^{-3}$

$\mathrm{W} \mathrm{m} \mathrm{m}^{-2}$

$\mathrm{s}^{-1}$

$\mathrm{s}^{-1}$

mmole $\mathrm{m}^{-3}$

$\mathrm{s}^{-1}$

$\mathrm{s}^{-1}$
$\mathrm{~s}^{-1}$
$\mathrm{~s}^{-1}$
$\mathrm{~s}^{-1}$

$\mathrm{m} \mathrm{s}^{-1}$
$\mathrm{~s}^{-1}$

and grazing is formulated as:

$$
\begin{aligned}
G_{p} & =g_{z} \frac{P^{2}}{(P+D) K_{z}+P^{2}+D^{2}} Z \\
G_{d} & =g_{z} \frac{D^{2}}{(P+D) K_{z}+P^{2}+D^{2}} Z .
\end{aligned}
$$

Other modeled biogeochemical processes include phytoplankton mortality, zooplankton mortality (that is not reinjected in the surface layer but is remineralized below), zooplankton excretion, fecal pellet production, detritus sedimentation, detritus remineralization, nitrification and dissolved organic matter break down.

Below the twelveth vertical layer (at depth $z_{\text {bio }}$ ), remineralization processes prevail. Remineralization is parameterized by a decay of all variables into nitrate, and a local (i.e., on the local vertical) redistribution of zooplankton mortality:

$$
\begin{gathered}
S\left(\mathrm{NO}_{3}\right)=\tau_{r}\left(\mathrm{NH}_{4}+P+Z+D+D O M\right)+\partial_{z} f \\
S\left(\mathrm{NH}_{4}\right)=-\tau_{r} \mathrm{NH}_{4} \\
S(P)=-\tau_{r} P \\
S(Z)=-\tau_{r} Z \\
S(D)=-\tau_{r} D \\
S(D O M)=-\tau_{r} D O M
\end{gathered}
$$


Table 3. Optical parameters.

$\begin{array}{lc}\text { Symbol } & \text { Value } \\ k_{r 0} & 0.225 \\ k_{b 0} & 0.0232 \\ \chi_{r p} & 0.037 \\ \chi_{b p} & 0.074 \\ e_{r} & 0.629 \\ e_{b} & 0.674 \\ R_{C: N} & 6.625 \\ R_{C: C h l} & 60 \\ r_{p i g} & 0.7\end{array}$

Unit

$\mathrm{m}^{-1}$

$\mathrm{m}^{-1}\left(\mathrm{mgChlm}^{-3}\right)^{-\mathrm{e}_{\mathrm{r}}}$

$\mathrm{m}^{-1}\left(\mathrm{mgChlm}^{-3}\right)^{-\mathrm{e}_{\mathrm{b}}}$

$\mathrm{mmoleC} / \mathrm{mmoleN}$

$\mathrm{mmoleC} / \mathrm{mgChl}$

with the remineralization flux defined as:

$$
\begin{gathered}
f\left(z_{\text {bio }}\right)=\int_{0}^{z b i o} m_{z} Z^{2} d z \\
f(z)=f\left(z_{b i o}\right)\left(\frac{z}{z_{b i o}}\right)^{-0.858} .
\end{gathered}
$$

We add a condition for no deposition on the ocean floor, $f\left(z_{\text {bottom }}\right)=0$., where $z_{\text {bottom }}$ is the depth of the last aquatic layer.

The photosynthetic available radiation at each depth $P A R(z)$ is computed from a two wavelength light absorption model ( $r$ and $b$ for red and blue, with parameters values in Table 3):

$$
\begin{gathered}
k_{r}=k_{r 0}+\chi_{r p} C h l^{e_{r}} \\
k_{b}=k_{b 0}+\chi_{b p} C h l^{e_{b}} \\
C h l=12 \frac{R_{C: N}}{r_{\mathrm{pig}} R_{C: C h l}} P \\
\operatorname{PAR}_{r}(0)=P A R_{b}(0)=\frac{0.43}{2} Q_{s o l} \\
\operatorname{PAR}_{r}(z)=P A R_{r}(z-d z) e^{-k_{r} d z} \\
\operatorname{PAR}_{b}(z)=P A R_{b}(z-d z) e^{-k_{b} d z} \\
\operatorname{PAR}_{(z)}=\operatorname{PAR}_{r}(z)+P A R_{b}(z)
\end{gathered}
$$

where $Q_{s o l}$ is the incoming solar radiation. 


\section{REFERENCES}

Abraham, E. R. 1998. The generation of plankton patchiness by turbulent stirring. Nature, 391, 577-580.

Abraham, E. R., C. S. Law, P. W. Boyd, S. J. Lavender, M. T. Maldonado and A. R. Bowie. 2000. Importance of stirring in the development of an iron-fertilized phytoplankton bloom. Nature, 407, 727-730.

Anderson, L. A. and A. R. Robinson. 2001. Physical and biological modeling in the Gulf Stream region Part II. Physical and biological processes. Deep-Sea Res. I, 48, 1139-1168.

Blanke, B. and P. Delecluse. 1993. Variability of the tropical Atlantic Ocean simulated by a general circulation model with two different mixed-layer physics. J. Phys. Oceanogr., 23, 1363-1388.

Blanke, B. and S. Raynaud. 1997. Kinematics of the Pacific equatorial undercurrent: an Eulerian and Lagrangian approach from GCM results. J. Phys. Oceanogr., 27, 1038-1053.

Blumen, W. 2000. Inertial oscillations and frontogenesis in a zero-potentialvorticity model. J. Phys. Oceanogr., 30, 31-39.

Dadou, I., V. Garçon, V. Andersen, G. R. Flierl and C. S. Davies. 1996. Impact of the North Atlantic equatorial current meandering on a pelagic ecosystem: A modeling approach. J. Mar. Res., 54, 311-342.

Davies-Jones, R. 1991. The frontogeneticalforcing of secondary circulations. Part I: The duality and generalization of the Q vector. J. Atmos. Sci., 48, 497-509.

Denman, K. L. and M. R. Abbott. 1994. Time scales of pattern evolution from cross-spectrum analysis of advanced very high resolution radiometer and coastal zone colar scanner imagery. J. Geophys. Res., 99, 7433-7442.

Denman, K. L. and T. Platt. 1976. The variance spectrum of phytoplankton in a turbulent ocean. J. Mar. Res., 34, 593-601.

Fasham, M. J. R., T. Platt, B. Irwin and K. Jones. 1985. Factors affecting the spatial pattern of the deep-chlorophyllmaximum in the region of the Azores front. Progr. Oceanogr., 14, 129-165.

Flierl, G. R. and C. S. Davis. 1993. Biological effects of Gulf Stream meandering. J. Mar. Res., 51, 529-560.

Foujols, M.-A., M. Lévy, O. Aumont and G. Madec. 2000. OPA 8.1 Tracer Model Reference Manual. Note technique du Ple de modlisation, Institut Pierre-Simon Laplace. http://www.ipsl. jussieu.fr

Gall, R. 1977. Some nonquasi-geostrophic effects in linear baroclinic waves. Mon. Wea. Rev., 105, 1039-1051.

Gill, A. E. 1982. Atmosphere-Ocean Dynamics, Academic Press. 662 pp.

Gower, J. F. R., K. L. Denman and R. L. Holyer. 1980. Phytoplankton patchiness indicates the fluctuations spectrum of mesoscale oceanic structure. Nature, 288, 157-159.

Halliwell, G. R. and P. Cornillon. 1989. Large scale SST anomalies associated with subtropical fronts in the western North Atlantic during FASINEX. J. Mar. Res., 47, 757-775.

Hart, J. E. 2000. On nonlinear corrections to the Ekman pumping. Phys. Fluids, 12, 131-135.

Hitchcock, G. L., A. J. Mariano and T. Rossby. 1993. Mesoscale pigment fields in the Gulf Stream: observations in a meander crest and trough. J. Geophys. Res., 98, 8425-8445.

Hourdin, F. and A. Armengaud. 1998. The use of finite-volume methods for atmospheric advection of trace species. Part I: test of various formulations in a general circulation model. Mon. Wea. Rev., 127, 822-837.

Hua, B. L., J. C. McWilliams and P. Klein. 1998. Lagrangian acceleration in geostrophic turbulence. J. Fluid Mech., 35, 1-22.

Klein, P. and B. L. Hua. 1990. The mesoscale variability of the sea surface temperature. An analytical and numerical model. J. Mar. Res., 48, 729-763. 
Klein, P., A.-M. Treguier and B. L. Hua. 1998. Three-dimensional stirring of thermohaline fronts. J. Mar. Res., 56, 589-612.

Lapeyre, G., B. L. Hua and P. Klein. 2001. Dynamics of the orientation of active and passive scalars in two-dimensional turbulence. Phys. Fluids, 13, 251-254.

Lapeyre, G., P. Klein and B. L. Hua. 1999. Do tracer gradient vectors align with strain vectors in 2-D flows? Phys. Fluids, 11, 3729-3737.

Ledwell, J. R., A. J. Watson and C. S. Law. 1993. Evidence for slow mixing across the pycnocline from an open-ocean tracer-release experiment. Nature, 364, 701-703.

Lee, D., P. Niiler, A. Warn-Varnas and S. Piacsek. 1994. Wind-driven secondary circulationin ocean mesoscale. J. Mar. Res., 52, 371-396.

Lee, M. M. and R. G. Williams. 2000. The role of eddies in the isopycnic transfer of nutrients and their impact on biological production. J. Mar. Res., 58, 895-917.

Lévy, M., A. Estublier and G. Madec. 2001. Choice of an advection scheme for biogeochemical models. (in press).

Lévy, M., L. Mémery and G. Madec. 2000. The onset of a bloom in the MEDOC area: mesoscale and high-frequency spatial variability. Deep-Sea Res. I, 47, 27-53.

Madec, G., M. Chartier, P. Delecluse and M. Crepon. 1991. A three-dimentional numerical study of deep water formation in the northwestern Mediterranean Sea. J. Phys. Oceanogr., 21, 1349-1371.

Madec, G., P. Delecluse, M. Imbard and C. Lévy. 1999. OPA 8.1 Ocean General Circulation Model Reference Manual, Note du Ple de modlisation, Institut Pierre-Simon Laplace. http://www.ipsl. jussieu.fr

Mahadevan, A. and D. Archer. 2000. Modeling the impact of fronts and mesoscale circulation on the nutrient supply and biogeochemistry of the upper ocean. J. Geophys. Res., 105, 1209-1225.

Mariotti, A., B. Legras and D. G. Dritschel. 1994. Vortex stripping and the erosion of coherent structures in two-dimensional flows. Phys. Fluids, 6, 3954-3962.

Martin, A. P. 2000. On filament width in oceanic plankton distributions. J. Plankton Res., 22, 597-602.

McGillicuddy Jr., D. J., A. R. Robinson and J. J. McCarthy. 1995. Coupled physical and biological modelling of the spring bloom in the North Atlantic (II): three dimensional bloom and post-bloom processes. Deep-Sea Res. I, 42, 1359-1398.

McGillicuddy Jr., D. J., A. R. Robinson, D. A. Siegel, H. W. Jannasch, R. Johnson, T. D. Dickey, J. McNeil, A. F. Michaels and A. H. Knap. 1998. Influence of mesoscale eddies on new production in the Sargasso Sea. Nature, 394, 263-265.

McWilliams, J. C., P. R. Gent and N. J. Norton. 1986. The evolution of balanced, low-modes vortices on the $\beta$-plane. J. Phys. Oceanogr., 16, 838-855.

Michaels, A. F. and A. H. Knap. 1996. Overview of the U.S. JGOFS Bermuda Atlantic time-series study and the hydrostation S program. Deep-Sea Res. II, 43, 157-198.

Oschlies, A. and V. Garçon. 1998. Eddy-induced enhancement of primary production in a model of the North Atlantic Ocean. Nature, 394, 266-269.

Perez, F. F., M. Gil-Coto and A. F. Rios. 2001. Large and mesoscale variability of the water masses and the deep chlorophyll maximum in the Azores front. J. Geophys. Res., (submitted).

Pollard, R. T. and L. A. Regier. 1992. Vorticity and vertical circulation at an ocean front. J. Phys. Oceanogr., 22, 609-625.

Protas, B., A. Babiano and K. R. Kevlahan. 1999. On geometrical alignment properties of two-dimensional forced turbulence. Physica D, 128, 169-179.

Siegel, D. A., D. J. McGillicuddy, Jr. and E. A. Fields. 1999. Mesoscale eddies, satellite altimetry, and new production in the Sargasso Sea. J. Geophys. Res., 104, 13,359-13,379.

Smith, C. L., K. J. Richards and M. J. R. Fasham. 1996. The impact of mesoscale eddies on phytoplanktondynamics in the upper ocean. Deep-Sea Res. I, 43, 1807-1832. 
Snyder, C., W. C. Skamarock and R. Rotunno. 1991. A comparison of primitive-equation and semigeostrophic simulations of baroclinic waves. J. Atmos. Sci., 48, 2179-2194.

Spall, M. A. 1995. Frontogenesis, subduction, and cross-front exchange at upper ocean fronts. J. Geophys. Res., 100, 2543-2557.

- 1997. Baroclinic jets in confluent flow. J. Phys. Oceanogr., 27, 1054-1071.

Spall, S. A. and K. J. Richards. 2000. A numerical model of mesoscale frontal instabilities and plankton dynamics-I. Model formulation and initial experiments. Deep-Sea Res. I, 47, 12611301.

Stammer, D. 1997. Global characteristics of ocean variability estimated from regional TOPEX/ POSEIDON altimeter measurements. J. Phys. Oceanogr., 27, 1743-1769.

Strass, V. H. 1992. Chlorophyll patchiness caused by mesoscale upwelling at fronts. Deep-Sea Res., 39, 75-96.

Van Leer, B. 1977. Towards the ultimate conservative difference scheme. IV. A new approach to numerical convection. J. Comput. Phys., 51, 497-513.

Wang, D.-P. 1993. Model of frontogenesis: Subduction and upwelling. J. Mar. Res., 51, 497-513.

Washburn, L., B. M. Emery, B. H. Jones and D. G. Ondercin. 1998. Eddy stirring and phytoplankton patchiness in the subarctic North Atlantic in late summer. Deep-Sea Res., 45, 1411-1439.

Whitaker, J. S. 1993. A comparison of primitive and balance equations simulations of baroclinic waves. J. Atmos. Sci., 50, 1519-1530.

Woods, J. 1988. Mesoscale upwelling and primary production, in Toward a Theory on BiologicalPhysical Interactions in the World Ocean, B. J. Rothschild, ed., Kluwer Academic Publishers, 7-38.

Wunsch, C. 1997. The vertical partition of oceanic horizontal kinetic energy. J. Phys. Oceanogr., 27, 1770-1794.

$\mathrm{Xu}, \mathrm{Q}$. 1990. Cold and warm frontal circulations in an idealized moist semigeostrophic baroclinic wave. J. Atmos. Sci., 47, 2337-2352.

- 1992. Ageostrophic pseudovorticity and geostrophic C-vector forcing-A new look at the Q vector in three dimensions. J. Atmos. Sci., 49, 981-990.

Yentsch, C. S. and D. A. Phinney. 1985. Rotary motions and convection as a means of regulating primary production in warm core rings. J. Geophys. Res., 90, 3237-3248.

Yoshimori, A. and M. J. Kishi. 1994. Effects of interaction between two warm-core rings on phytoplankton distribution. Deep Sea Res. I, 41, 1039-1052.

Received: 9 November, 2000; revised: 31 May, 2001. 